\title{
The Possible Cardiopulmonary and Cerebral Toxic Effects of Sildenafil Citrate (Viagra) on Adult Male Albino Rats
}

\author{
Heba Y. Mohammed, Nabil N. Rezk, Zeinab A. Abdel Haleem', and Safaa \\ Mohamed Shaker²
}

\author{
${ }^{1}$ Forensic Medicine and Clinical Toxicology Department \\ 2 Histology Department \\ Faculty of Medicine, Ain Shams University, Cairo, Egypt
}

\begin{abstract}
It has been asked whether sildenafil safety live up to its expectations or not. Most of the previous studies stated that sildenafil is safe and well tolerated by most users without serious effects. The drug has attained great popularity and widely used even without prescription or as one of the over the counter preparation. So, this work was carried out to assess the possible cardio pulmonary and cerebral toxicities of sildenafil citrate in adult male albino rats. The study included three parts; acute, short term and chronic toxicity studies. At the end of each experimental study, the animals were subjected to ECG and blood pressure recording. Then blood samples were collected for estimation of the levels of enzymes relevant to cardiotoxicity (CPK, CPKMB, LDH and SGOT). Furthermore, histopathological examination of the rats' heart, lung and brain was carried out by light microscopy. The results showed evident cardiac toxicity in the form of ECG and blood pressure changes as well as elevated cardiac enzymes. Histopathological changes in the chronic toxicity group were more severe and extensive than either acute or short term study groups. So, it can be concluded that sildenafil caused biochemical and histopathological alterations in the heart along with histopathological changes in the lung and brain that correlated with the duration of administration. It is recommended that sildenafil should be used only on medical prescription. Also, serum levels of CPK, CPKMB, LDH and ECG recording are sensitive indicators for sildenafil induced cardiac toxicity.
\end{abstract}

\section{Introduction}

$\mathrm{I}$ n 1998, sildenafil was approved by US food and drug administration as the first medication indicated for treatment of erectile dysfunction (Khera and Goldstein, 2011). It has been used in pulmonary hypertension, Raynaud's phenomenon and vertebro-basilar insufficiency (Han et al., 2012). Sildenafil is a cyclic guanosine specific phasphodiesterase type 5 inhibitor that prevents the metabolism of cyclic guanosine which produces smooth muscle relaxation (Polak et al., 2003) especially, within the corpora cavernosa of the penis (Marmon and Kessler, 1999) and ultimately enhances penile tumescence. Sildenafil produces a decrease in systolic and diastolic blood pressure (Vardi et al., 2002) and an array of toxicities due to inhibition of other types of phosphodiesterase. However, many case reports indicated that sildenafil can produce profound hypotension leading to a decrease in coronary perfusion and myocardial infarction (Kekilli et al., 2005). Sildenafil was used in treatment of pulmonary artery hypertension with great success. It is available freely even over the counter, used by millions of men all over the world. Many side effects and toxicities were reported about sildenafil whether in paediatric patients who treated with sildenafil for pulmonary artery hypertension or adults who use it for erectile dysfunction. However its long term toxic effects were not properly evaluated (Fagelman et al., 2001).

So, this work was carried out to assess the acute, short term and chronic toxicities of sildenafil on the heart, lung and brain in adult male albino rats.

\section{Materials and methods}

\section{Drug}

Sildenafil citrate: It was in the form of blue film coated rounded - diamond shaped tablets (100 mg/tablet). It was obtained from Pfizer pharmaceutical company. It was dissolved in distilled water and freshly prepared before given to the experimental animals. 


\section{Animals}

Adult male albino rats were chosen for the experiment from the medical research centre, Faculty of Medicine Ain Shams University of average weight 100-150 g.

The study was done in the Medical Research

Centre (MRC) of Ain Shams University and the application form of the research was written and signed according to the ethical considerations and the guidelines of MRC. All animals were kept under the same environmental conditions throughout the study duration.

\section{Experimental design}

The study consists of three parts:

- Part 1: Acute toxicity study for $24 \mathrm{hrs}$.

- Part 2: Short term chronic toxicity study, it extends for 8 weeks.

- Part 3: Chronic toxicity study which lasts for 12 weeks.

This is according to the method of Cuschieri and Backer (1977).

\section{Acute toxicity study}

This study included 30 adult male albino rats weighing 100-150 g, which were divided into three equal groups as follows:

- Group Ia: negative control group. The animals of this group were kept in the same environment without handling to demonstrate the normal basic parameters.

- Group IIa (positive control): This group received $1 \mathrm{ml}$ of distilled water by gavage for one day only.

- Group IIIa: Acute toxic sildenafil group. Rats in this group were given single doses of sildenafil of 200 $\mathrm{mg} / \mathrm{kg}$ by gavage. According to Abbott et al., (2004), this dose represents the maximum non lethal dose of sildenafil in rats, which is nearly half the LD50 (300$500 \mathrm{mg} / \mathrm{kg}$ ).

\section{Short term toxicity study}

Thirty adult male albino rats of the same weight as in the acute toxicity study. They were equally divided into three groups:

- Group Ib: negative control group.

- Group IIb: positive control group which received $1 \mathrm{ml}$ of distilled water daily by gavage for 8 weeks.

- Group IIIb: the animals were given $100 \mathrm{mg} / \mathrm{kg}$ of sildenafil daily by gavage for 8 weeks. This dose was selected according to Abbott et al., (2004).

\section{Chronic toxicity study}

This group also included thirty adult male albino rats and divided as the two previous study designs into three equal groups as follows:

- Group Ic: negative control group.

- Group IIc: The rats received $1 \mathrm{ml}$ of distilled water by gavage daily for 12 weeks.

- Group IIIc: The animals of this group were given $20 \mathrm{mg}$ of sildenafil daily by gavage for 12 weeks. This dose represents the highest therapeutic dose according to Abbott et al., (2004).

\section{Experimental parameters I-ECG recording}

At the end of each experimental period, the animals of each study (acute, short term and chronic) were anesthetized by ether inhalation and the electrocardiographic changes were recorded on lead II that gives good signals. The paper chart speed for ECG recording by oscillograph was $50 \mathrm{~mm} / \mathrm{seconds}$ (Dewall et al., 1971). The heart rate/min, QRS duration and ST segments deflections were recorded.

\section{II-Blood pressure recording}

After the effect of ether inhalation is terminated, the rats were given urethane $(1.75-2 \mathrm{~g} / \mathrm{kg}$ in the peritoneal cavity as $25 \%$ aqueous solution freshly prepared for each study group, according to Ghosh (1971). After maintenance of anaesthesia, muscle were separated along the mid line, trachea was exposed and a transverse cut was made in between two rings so as to introduce a tracheal cannula to maintain the respiration 
of animals, the cannula was held in portion by a delicate twin ligature. The carotid artery on the left side of the heart was exposed, dissected then a clamp was applied on the carotid artery proximal to the chest as possible. A fine thread was passed around the artery. A cut was made on the artery (just proximal to the thread mentioned above), through which a heparinised arterial cannula was inserted gently and directed to the heart and firmly fixed by the thread. The three way valve was turned so that the blood pressure transducer remained in communication with the cannula, then the blood pressure was recorded on the paper chart of the oscillograph at a speed of $0.25 \mathrm{~mm} / \mathrm{sec}$ (Dewhurst et al., 2006).

\section{III-Biochemical parameters}

Blood samples were taken directly from the carotid artery (through the cannula used for blood pressure recording) in a dry clean tube, and then centrifuged and the serum was separated for spectrophotometric determination of lactic acid dehydrogenase (LDH) according to Callbreath (1992) and creatine phosphokinase (CPK) \& CPKMB according to Wolfson et al., (1991). Also serum glutamic oxaloacetic transaminase (SGOT) was determined according Reitman and Frankul (1957).

\section{IV-Histopathological study}

The animals of each study group were dissected; the heart and the lungs were obtained. Also the animals were decapitated, the head of each animal was carefully dissected and the cranium was cut using strong sharp scalpel. Then, the brain was exposed and put immediately in the fridge for at least 6-12 hours. The tissues were fixed in $10 \%$ formalin and processed for paraffin blocks then minted and stained with Haematoxylin and Eosin stain (Hx \& E) and subjected to light microscope examination. (Drury and Wallington, 1980).

\section{Statistical analysis}

The results were obtained; statistical analysis was done using SPSS windows-version 17 . The mean and standard deviation were calculated and used for description of quantitative variables. Student t-test was used for comparison between two groups while, ANOVA one way statistical analysis was used for comparison between more than two groups. In all tests the probability $(\mathrm{P})$ was used and significance was set at $\mathrm{P}<0.05$.

\section{Results}

\section{Experimental results}

\section{I-Acute toxicity study}

\section{ECG and blood pressure}

ECG and blood pressure changes as shown in table (1) shows insignificant difference in the ECG records (heart rate, QRS duration and ST segment depression from the isoelectric line) between negative control (Ia) and positive control (IIa) groups. There was also insignificant difference in the systolic and diastolic blood pressure of these two groups (Ia and IIa).

On the other hand, there was significant increase in heart rate as well as significant depression of the ST segment in sildenafil acute toxic dose group (IIIa) when compared with the negative control group (Ia). In contrast, there was significant decrease in QRS duration and both systolic and diastolic blood pressure in sildenafil acute toxic dose group (IIIa) when compared with the negative control group (Ia).

\section{Biochemical results}

Regarding serum levels of the cardiac enzymes; CPK, CPKMB, LDH and SGOT. There was insignificant difference in their levels between negative control (Ia) and positive control (IIa) groups as shown in table (2).

The same table also shows significant increase in the levels of CPK, CPKMB, LDH, and SGOT in sildenafil acute toxic dose group (IIIa) when compared to negative control group (Ia).

\section{II-Short term toxicity study}

\section{ECG and blood pressure}

ECG and blood pressure changes as shown in table (3) shows insignificant difference in the ECG records (heart rate, QRS duration and ST segment depression from the isoelectric line) and both systolic and diastolic blood pressure between negative control (Ib) and positive control (IIb) groups.

On comparing sildenafil group (IIIb) with negative control group (Ib), there was significant increase in the heart rate and ST segment depression. In contrast, there was significant decrease in QRS complex duration and in both systolic and diastolic blood pressure

\section{Biochemical results}

There was insignificant difference in the levels of CPK, CPKMB, LDH and SGOT between negative control group (Ib) and positive control group (IIb) as shown in table (4).

The same table shows significant increase in the CPK, CPKMB, LDH and SGOT levels in the sildenafil group (IIIb) in comparison with negative control group $(\mathrm{Ib})$.

\section{III-Chronic toxicity study}

\section{ECG and blood pressure results}

There was insignificant difference in the ECG records (heart rate, QRS duration and ST segment depression from the isoelectric line) and both systolic and diastolic blood pressure between negative control group (Ic) and positive control group (IIc) as shown in table(5).

The same table also shows that sildenafil administration for 12 weeks caused significant increase in the heart rate and ST segment depression. Also significant decrease in QRS complete duration and both systolic and diastolic blood pressure of chronic sildenafil toxicity group (IIIc) when compared with negative control group (Ic). 


\section{Biochemical results}

There was insignificant difference in the levels of CPK, CPKMB, LDH and SGOT between negative control groups (Ic) compared to positive control group (IIc) as shown in table (6).

After 12 weeks of sildenafil treatment, there was significant increase in the levels of CPK, CPKMB, LDH and SGOT of chronic sildenafil toxicity group (IIIc) when compared with negative control group (Ic).

ANOVA one way statistical analysis in table (7) shows that the calculated variance ratio for ECG, blood pressure as well as cardiac enzymes levels is greater than the tabulated ratio. Thus, there was significant difference in all the experimental parameters on comparing the three sildenafil groups (IIIa, IIIb and IIIc) with each other.

\section{Histopathological changes \\ I-Control groups}

Gross Examinations of the heart, lung and brain showed that they were of normal size, soft in consistency and not congested.

The heart of these group showed, similarity in the structure with branching and anastomosing muscle fibres. Muscle fibres composed of cardiomyocytes connected together by intercalated discs. The longitudinally cut muscle fibres appeared cylindrical in shape with transverse striations and were separated by slit left spaces. Transversely cut fibres were polygonal in shape with small blood capillaries. Cardiomyocytes had acidophilic cytoplasm with oval vesicular central nuclei (figure 1).

The lung tissues of this group showed the normal alveolar pattern separated by this inter alveolar septa. The alveoli appeared well inflated lined by two types of pneumocytes; the flat type (I) and few cuboidal types (II). Blood capillaries were present in between the alveoli as shown in figure (2).

The Brain tissues showed normal appearance of all six layers of cerebral cortex. The upper three layers appear plexiform with nerve cells arranged horizontally. Next, is the granular layer with small pyramidal neurones and next to this is the outer pyramidal cell layer. Below, there are the lower three layers and granular pyramidal neurones. The inner most layer is polymorphous layer that lacks pyramidal cells. Beneath the cortex is the white matter. The neurons are present in lacunae as shown in figure (3).

\section{II-Acute toxicity study group}

The heart of sildenafil group showed congestion in between the cardiac muscle fibres as shown in figure (4). Furthermore, the cardiac muscle fibres showed areas of marked congestion, oedema, disarray of the cardiac muscle fibres together with blood onward the muscle fibres (figure 5).

The lung tissues of sildenafil group showed massive interstitial haemorrhage, collapsed alveoli and mild thickening of the inter alveolar septa as shown in figure (6).

Figure (7) showed congested blood vessels and oedema in between the alveoli with mild cellular infiltration.

The brain tissues of sildenafil group showed mild shrinkage of neurones surrounded by vacuoles with normal areas (figure 8). Figure (9) showed marked shrinkage with their neurones appear inflamed filling their lacunae.

\section{III-Short term toxicity study}

The heart tissues of sildenafil group showed congestion in between the cardiac muscle fibres and shrinkage of muscle fibres with some connective tissues in between as shown in figure (10). In addition figure (11) showed slight swelling of the cardiac muscle fibre while others appear normal.

The lung tissues of sildenafil group showed massive peri bronchiolar cellular infiltration. Many alveoli appeared collapsed with thickened interalveolar septa as shown in figure (12). Also, there was marked congestion of the blood vessels and thickened interalveolar septa and collapsed alveoli (Figure 13).

The brain tissues of sildenafil group showed that the neurons appeared markedly shrunken and surrounded by vacuoles and inflammatory cells (figure 14). Nevertheless the brain tissues showed widened blood vessels together with shrinkage of the neurons and slight areas of degenerations (figure 15).

\section{IV-Chronic Toxicity study}

The heart tissues of sildenafil group showed marked cloudy swelling of the cardiac muscle fibres, shrinkage and increased connective tissue in between as shown in figure (16). In addition to these changes figure (17) showed marked and extensive degeneration of the cardiac muscle fibres and increased connective tissue in between.

The lung tissues of sildenafil group showed that all the alveoli were collapsed with marked thickening of the inter-alveolar septa (figure 18 \& 19).

The brain tissues of sildenafil group revealed shrinkage of nearly all neurones which appeared surrounded by vacuoles, widened blood vessels and chronic round cell infiltration as shown in figure (20). In addition, figure (21) showed intense widening of the blood vessels, large vacuoles, shrinkage and degeneration of all neurones.

Table (1): Student "t" test statistical analysis of the ECG records (heart rate, QRS, ST segment) and blood pressure in the negative control (Ia), positive control (IIa) and sildinafil acute toxicity (IIIa) groups.

\begin{tabular}{|l|l|c|c|c|} 
Parameters & Heart (rate/min) & QRS (msec) & ST & Blood pressure (mmHg)
\end{tabular}




\begin{tabular}{|c|c|c|c|c|c|}
\hline \multirow{2}{*}{ Groups } & & & & Systolic & Diastolic \\
\hline & $\mathrm{X} \pm \mathrm{SD}$ & $\mathrm{X} \pm \mathrm{SD}$ & $\mathrm{X} \pm \mathrm{SD}$ & $\mathrm{X} \pm \mathrm{SD}$ & $\mathrm{X} \pm \mathrm{SD}$ \\
\hline Group Ia & $375 \pm 45.4$ & $2.2 \pm 0.2$ & $0.4 \pm 0.15$ & $118.5 \pm 4.0$ & $85 \pm 5.5$ \\
\hline \multirow[t]{3}{*}{ Group IIa } & $373 \pm 35.9$ & $2.1 \pm 0.18$ & $0.35 \pm 0.12$ & $120 \pm 3.9$ & $85.9 \pm 5.6$ \\
\hline & 0.11 & 0.50 & 0.83 & 0.88 & 0.37 \\
\hline & $>0.05$ & $>0.05$ & $>0.05$ & $>0.05$ & $>0.05$ \\
\hline \multirow[t]{3}{*}{ Group IIIa } & $420 \pm 45.0$ & $1.8 \pm 0.10$ & $0.8 \pm 0.2$ & $58.5 \pm 3.5$ & $37.0 \pm 4.2$ \\
\hline & 2.25 & 5.7 & 5.7 & 35 & 12 \\
\hline & $<0.05$ & $<0.05$ & $<0.05$ & $<0.05$ & $<0.05$ \\
\hline
\end{tabular}

Where $t_{1} p_{1}$ comparison of group IIa with negative control, $t_{2} p_{2}$ comparison of group IIIa with negative control, $P$ $<0.05$ significant and $P>0.05$ insignificant.

Table (2): Student " $t$ " test of serum CPK, CPKMB, LDH and SGOT in negative control (Ia), positive control (IIa) and sildenafil acute toxicity (IIIa) groups.

\begin{tabular}{|c|c|c|c|c|}
\hline \multirow{2}{*}{ Groups } & CPK (IU/L) & CPKMB (IU/L) & LDH (IU/L) & SGOT (IU/L) \\
\hline & $\mathrm{X} \pm \mathrm{SD}$ & $\mathrm{X} \pm \mathrm{SD}$ & $\mathrm{X} \pm \mathrm{SD}$ & $\mathrm{X} \pm \mathrm{SD}$ \\
\hline Group Ia & $62.3 \pm 9.3$ & $25 \pm 3.2$ & $198.5 \pm 15.5$ & $23.8 \pm 2.27$ \\
\hline \multirow[t]{3}{*}{ Group IIa } & $65.9 \pm 9.5$ & $25.2 \pm 3$ & $201.0 \pm 16$ & $24 \pm 3$ \\
\hline & 0.87 & 0.15 & 0.35 & 0.16 \\
\hline & $>0.05$ & $>0.05$ & $>0.05$ & $>0.05$ \\
\hline \multirow[t]{3}{*}{ Group IIIa } & $522.5 \pm 21.1$ & $70 \pm 5$ & $1169.2 \pm 58.5$ & $102.0 \pm 11.8$ \\
\hline & 65 & 22.5 & 51.08 & 21.1 \\
\hline & $<0.05$ & $<0.05$ & $<0.05$ & $<0.05$ \\
\hline
\end{tabular}

Where $t_{1} p_{1}$ comparison of group IIa with negative control, $t_{2} p_{2}$ comparison of group IIIa with negative control, $P$ $<0.05$ significant and $P>0.05$ insignificant.

Table (3): Student " $t$ " test statistical analysis of the ECG changes (heart rate, QRS, ST segment) and blood pressure changes in the negative control (Ib), positive control (IIb) and sildenafil short term toxicity (IIIb) groups.

\begin{tabular}{|c|c|c|c|c|c|}
\hline \multirow{3}{*}{ Groups } & \multirow{2}{*}{ Heart (rate/min) } & \multirow{2}{*}{ QRS (msec) } & \multirow{2}{*}{ ST } & \multicolumn{2}{|c|}{ Blood pressure (mmHg) } \\
\hline & & & & Systolic & Diastolic \\
\hline & $\mathrm{X} \pm \mathrm{SD}$ & $\mathrm{X} \pm \mathrm{SD}$ & $\mathrm{X} \pm \mathrm{SD}$ & $\mathrm{X} \pm \mathrm{SD}$ & $\mathrm{X} \pm \mathrm{SD}$ \\
\hline Group Ib & $370 \pm 40.5$ & $2.2 \pm 0.7$ & $0.38 \pm 0.12$ & $120 \pm 5.7$ & $87.0 \pm 5$ \\
\hline \multirow[t]{3}{*}{ Group IIb } & $363 \pm 42.0$ & $2.15 \pm 0.1$ & $0.41 \pm 0.13$ & $121 \pm 6$ & $85.9 \pm 4.9$ \\
\hline & 0.29 & 0.71 & 0.23 & 0.41 & 0.50 \\
\hline & $>0.05$ & $>0.05$ & $>0.05$ & $>0.05$ & $>0.05$ \\
\hline \multirow[t]{3}{*}{ Group IIIb } & $460 \pm 39.5$ & $1.5 \pm 0.11$ & $0.85 \pm 0.22$ & $60 \pm 3.6$ & $56.0 \pm 3.5$ \\
\hline & 5.0 & 16.8 & 5.9 & 20 & 10.3 \\
\hline & $<0.05$ & $<0.05$ & $<0.05$ & $<0.05$ & $<0.05$ \\
\hline
\end{tabular}

Where $t_{1} p_{1}$ comparison of group IIb with negative control, $t_{2} p_{2}$ comparison of group IIIb with negative control, $P$ $<0.05$ significant and $P>0.05$ insignificant.

Table (4): Student " $t$ " test statistical analysis of serum CPK, CPKMB, LDH and SGOT of the negative control (Ib), positive control (IIb) and sildenafil short term toxicity IIIb groups.

\begin{tabular}{|c|c|c|c|c|}
\hline \multirow{2}{*}{$\begin{array}{l}\text { Parameters } \\
\text { Groups }\end{array}$} & CPK (IU/L) & CPKMB (IU/L) & LDH (IU/L) & SGOT (IU/L) \\
\hline & $\mathrm{X} \pm \mathrm{SD}$ & $\mathrm{X} \pm \mathrm{SD}$ & $\mathrm{X} \pm \mathrm{SD}$ & $\mathrm{X} \pm \mathrm{SD}$ \\
\hline Group Ib & $65.3 \pm 2.9$ & $25.5 \pm 2.9$ & $206.5 \pm 21.2$ & $21.0 \pm 1.1$ \\
\hline \multirow[t]{3}{*}{ Group IIb } & $66.0 \pm 2.5$ & $25.9 \pm 3.1$ & $204.0 \pm 10$ & $21.2 \pm 1.1$ \\
\hline & 0.58 & 0.3 & 0.54 & 0.40 \\
\hline & $>0.05$ & $>0.05$ & $>0.05$ & $>0.05$ \\
\hline \multirow[t]{3}{*}{ Group IIIb } & $400 \pm 13.12$ & $55.5 \pm 3.3$ & $933 \pm 23.5$ & $118 \pm 12.5$ \\
\hline & 15.1 & 9.4 & 145.3 & 24.25 \\
\hline & $<0.05$ & $<0.05$ & $<0.05$ & $<0.05$ \\
\hline
\end{tabular}

Where $t_{1} p_{1}$ comparison of group IIb with negative control, $t_{2} p_{2}$ comparison of group IIIb with negative control, $P$ $<0.05$ significant and $P>0.05$ insignificant. 
Table (5): Student " $t$ " test statistical analysis of the ECG changes (heart rate, QRS, ST segment) and blood pressure changes in negative control (Ic), positive control (IIIc) and sildenafil chronic toxicity (IIIc) groups.

\begin{tabular}{|c|c|c|c|c|c|}
\hline \multirow{3}{*}{ Groups } & \multirow{2}{*}{ Heart (rate/min) } & \multirow{2}{*}{ QRS (msec) } & \multirow{2}{*}{ ST } & \multicolumn{2}{|c|}{ Blood pressure (mmHg) } \\
\hline & & & & Systolic & Diastolic \\
\hline & $\mathrm{X} \pm \mathrm{SD}$ & $\mathrm{X} \pm \mathrm{SD}$ & $\mathrm{X} \pm \mathrm{SD}$ & $\mathrm{X} \pm \mathrm{SD}$ & $\mathrm{X} \pm \mathrm{SD}$ \\
\hline Group Ic & $335 \pm 6.4$ & $2.30 \pm 0.13$ & $0.37 \pm 0.15$ & $116.0 \pm 4.6$ & $91 \pm 7.5$ \\
\hline \multirow[t]{3}{*}{ Group IIc } & $336 \pm 6.5$ & $2.35 \pm 0.12$ & $0.36 \pm 0.13$ & $115.5 \pm 4.5$ & $90 \pm 7.4$ \\
\hline & 0.33 & 0.50 & 0.1 & 0.25 & 0.33 \\
\hline & $>0.05$ & $>0.05$ & $>0.05$ & $>0.05$ & $>0.05$ \\
\hline \multirow[t]{3}{*}{ Group IIIc } & $501 \pm 70$ & $1.9 \pm 0.1$ & $0.90 \pm 0.1$ & $60 \pm 8.5$ & $52 \pm 3.5$ \\
\hline & 8.3 & 4 & 5.3 & 19.9 & 13 \\
\hline & $<0.05$ & $<0.05$ & $<0.05$ & $<0.05$ & $<0.05$ \\
\hline
\end{tabular}

Where $t_{1} p_{1}$ comparison of group IIb with negative control, $t_{2} p_{2}$ comparison of group IIIb with negative control, $P$ $<0.05$ significant and $P>0.05$ insignificant.

Table (6): Student " $t$ " test statistical analysis of CPK, CPKMB, LDH and SGOT in the negative control (Ic), positive control (IIc) and sildenafil chronic toxicity (IIIc) groups.

\begin{tabular}{|c|c|c|c|c|}
\hline \multirow{2}{*}{ Groups } & CPK (IU/L) & CPKMB (IU/L) & LDH (IU/L) & SGOT (IU/L) \\
\hline & $\mathrm{X} \pm \mathrm{SD}$ & $\mathrm{X} \pm \mathrm{SD}$ & $\mathrm{X} \pm \mathrm{SD}$ & $\mathrm{X} \pm \mathrm{SD}$ \\
\hline Group Ic & $67.5 \pm 3.1$ & $29.5 \pm 4$ & $269 \pm 53.3$ & $24.0 \pm 3.3$ \\
\hline \multirow[t]{3}{*}{ Group IIc } & $66.7 \pm 2.9$ & $29.9 \pm 4.2$ & $280 \pm 52.1$ & $23.8 \pm 3.1$ \\
\hline & 0.26 & 0.33 & 0.20 & 0.15 \\
\hline & $>0.05$ & $>0.05$ & $>0.05$ & $>0.05$ \\
\hline \multirow[t]{3}{*}{ Group IIIc } & $570 \pm 13.3$ & $75.9 \pm 3.2$ & $924.7 \pm 80.5$ & $123.1 \pm 13.5$ \\
\hline & 100.5 & 7.75 & 23.8 & 18.3 \\
\hline & $<0.05$ & $<0.05$ & $<0.05$ & $<0.05$ \\
\hline
\end{tabular}

Where $t_{1} p_{1}$ comparison of group IIc with negative control, $t_{2} p_{2}$ comparison of group IIIc with negative control, $P<0.05$ significant and $P>0.05$ insignificant

Table(7): ANOVA one way statistical analysis of ECG, blood pressure, CPK, CPKMB, LDH and SGOT in sildenafil groups ; IIIa, IIIb and IIIc.

\begin{tabular}{|l|c|c|c|c|c|}
\hline \multirow{2}{*}{ Garameters } & Group IIIa & Group IIIb & Group IIIc & \multirow{2}{*}{ FC } & \multirow{2}{*}{ LSD } \\
\cline { 2 - 5 } & $\mathrm{X} \pm \mathrm{SD}$ & $\mathrm{X} \pm \mathrm{SD}$ & $\mathrm{X} \pm \mathrm{SD}$ & & \\
\hline Heart rate/min & $420 \pm 45.0$ & $460 \pm 39.5$ & $501 \pm 70$ & 112.6 & 24.3 \\
\hline QRS duration in msec & $1.8 \pm 0.10$ & $1.5 \pm 0.11$ & $1.9 \pm 0.1$ & 48 & 0.2 \\
\hline ST segment msec. & $0.80 \pm 0.20$ & $0.85 \pm 0.22$ & $0.90 \pm 0.1$ & 28.6 & 0.04 \\
\hline Systolic blood pressure in $\mathrm{mmHg}$ & $58.5 \pm 3.5$ & $60 \pm 3.6$ & $60 \pm 8.5$ & 5.68 & 0.3 \\
\hline Diastolic blood pressure in $\mathrm{mmHg}$ & $37 \pm 4.2$ & $56 \pm 3.5$ & $52 \pm 3.5$ & 2.4 & 0.1 \\
\hline CPK (IU/L) & $522 \pm 21.1$ & $400 \pm 13.12$ & $570 \pm 13.3$ & 30.5 & 24.9 \\
\hline CPKMB (IU/L) & $70 \pm 5$ & $55.5 \pm 3.3$ & $75.9 \pm 3.2$ & 6.28 & 0.35 \\
\hline LDH (IU/L) & $1169 \pm 58.5$ & $933 \pm 23.5$ & $924.7 \pm 80.5$ & 95.3 & 94.4 \\
\hline SGOT (IU/L) & $102 \pm 11.8$ & $118 \pm 12.5$ & $123.1 \pm 13.5$ & 42.13 & 3.3 \\
\hline
\end{tabular}

FC,F calculated., LSD: the least significant difference and tabulated $F=$ tabulated variance ratio at $P$ 0.05=2.1 


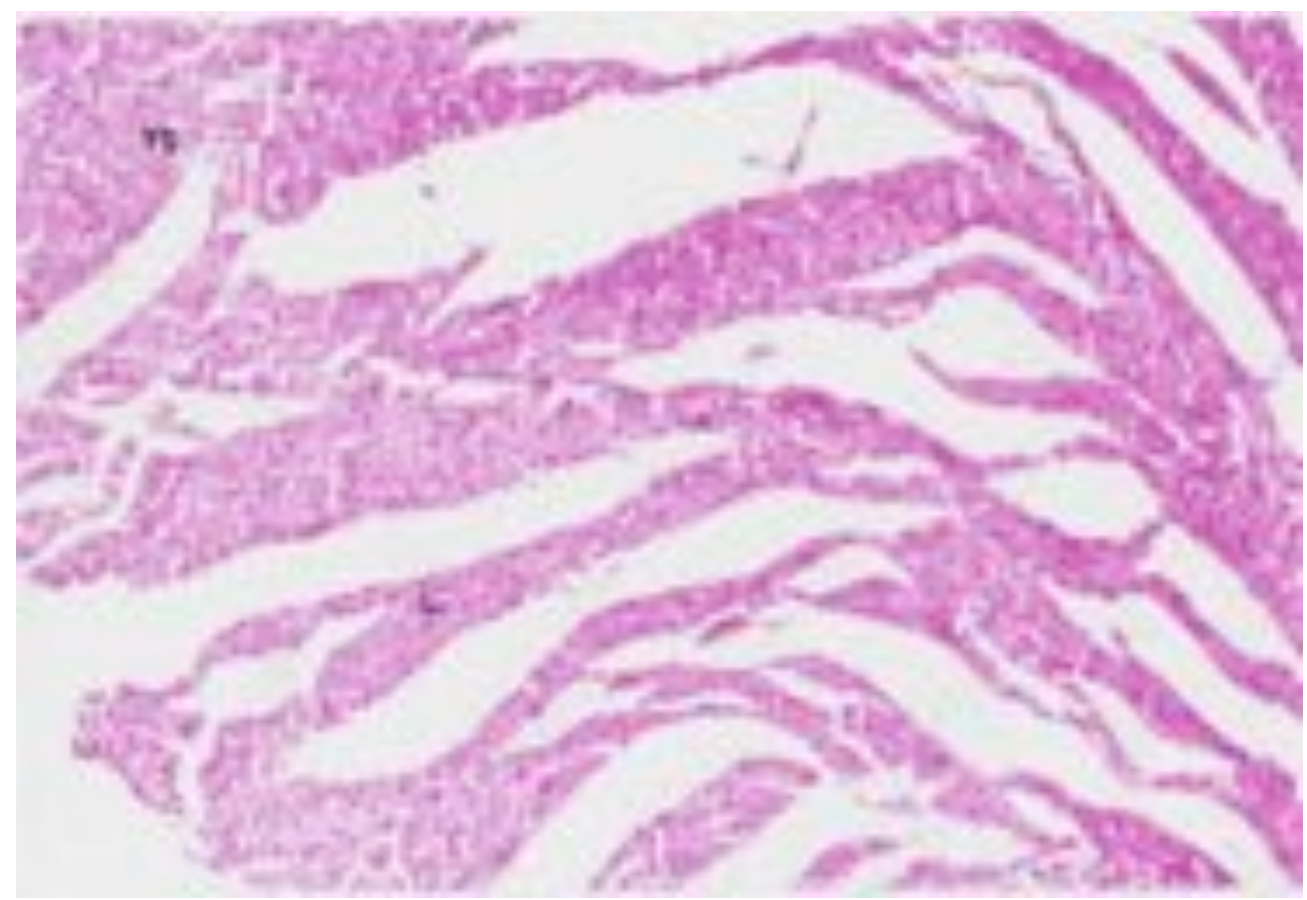

Figure (1) Photomicrograph of the control rat heart showing parallel cardiac muscle in different directions (L) and other are cut transverse (TS) (Hx. \& E X100).

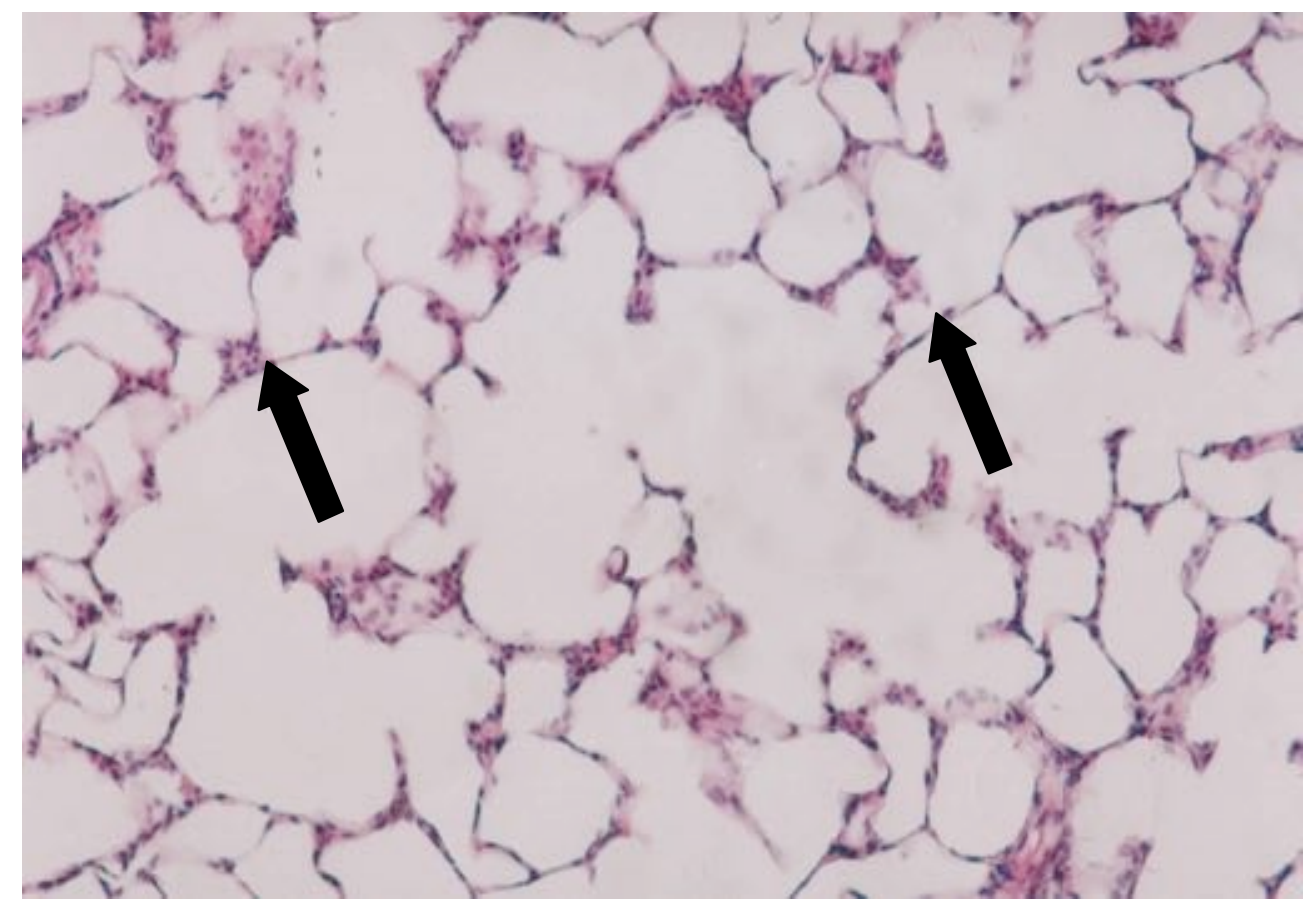

Figure (2): Photomicrograph of the control rat lung showing normal alveolar pattern with thin inter alveolar septa (arrow) (Hx. \& E X200). 


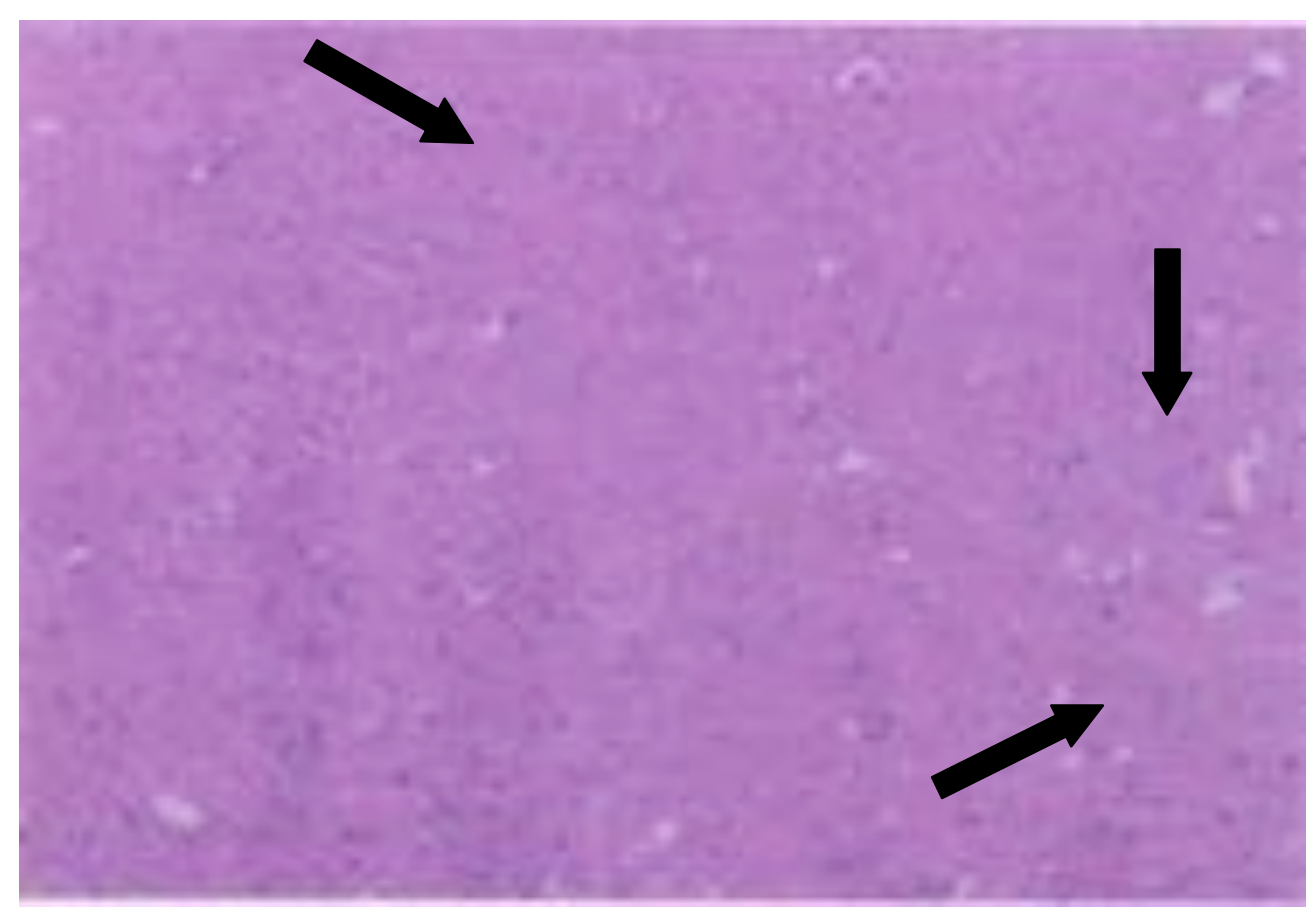

Figure (3): Photomicrograph of the control rat brain showing normal appearance of the layers of the cerebral cortex. The neurons are present in lacunae (arrow) (Hx. \& E X100).

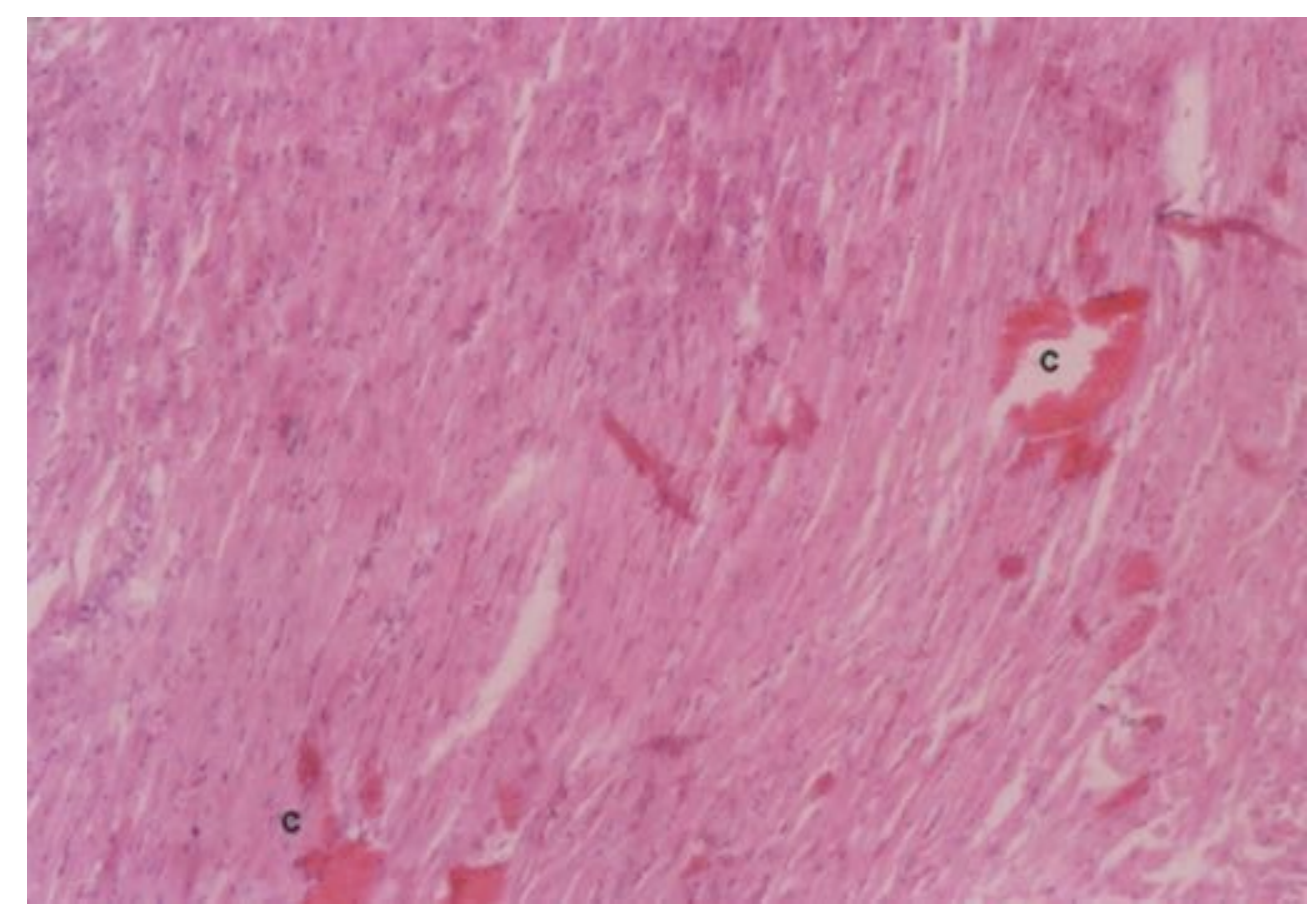

Figure (4): Photomicrograph of rat heart of acute toxicity group showing congestion(c) in between the cardiac muscle fibres. (Hx. \& E X100). 


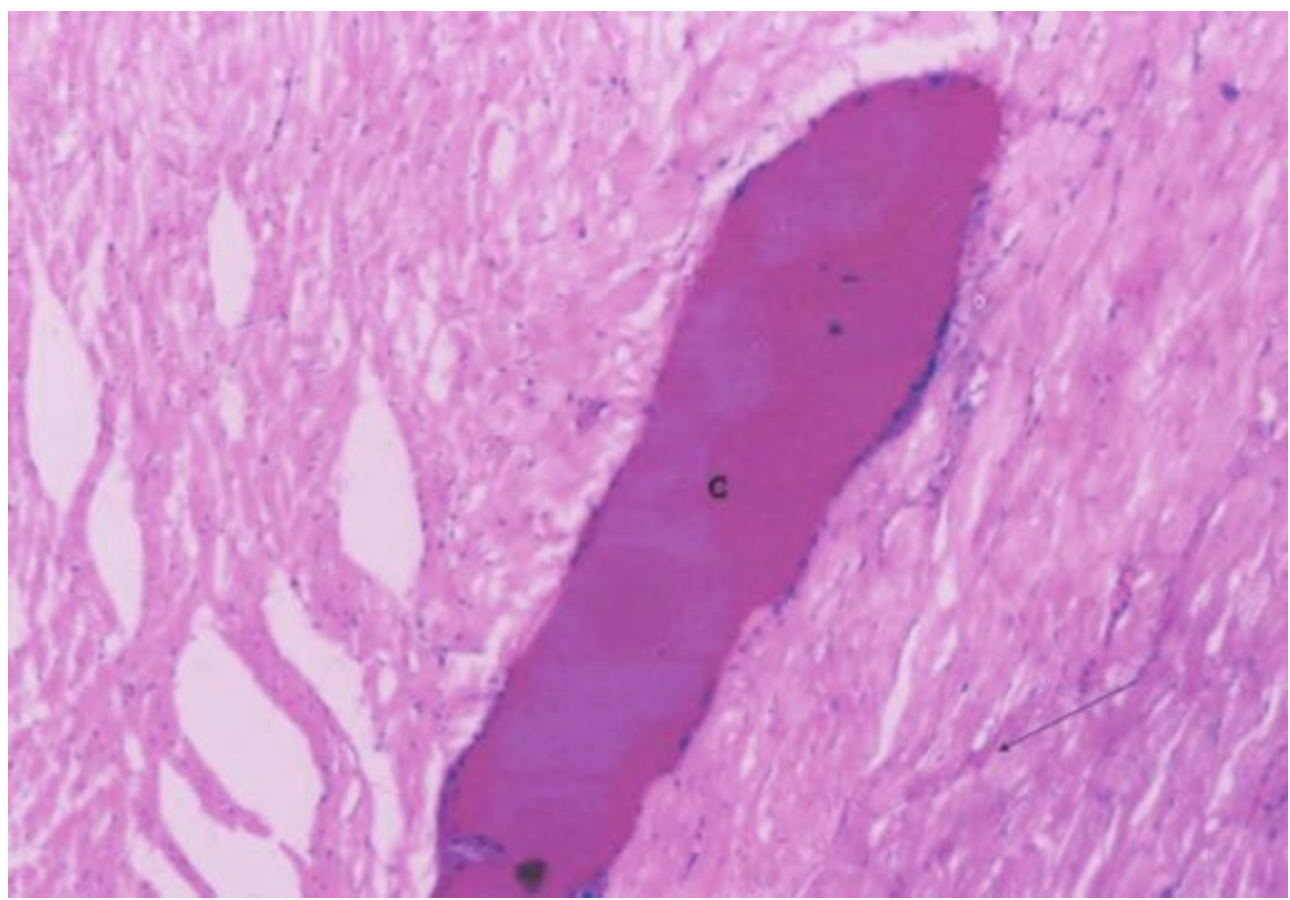

Figure (5): Another photomicrograph of rat heart of sildenafil acute toxicity group showing marked congestion, glycogen depletion and inflammatory cells surrounding congested vessel (c) (Hx \& E X100).

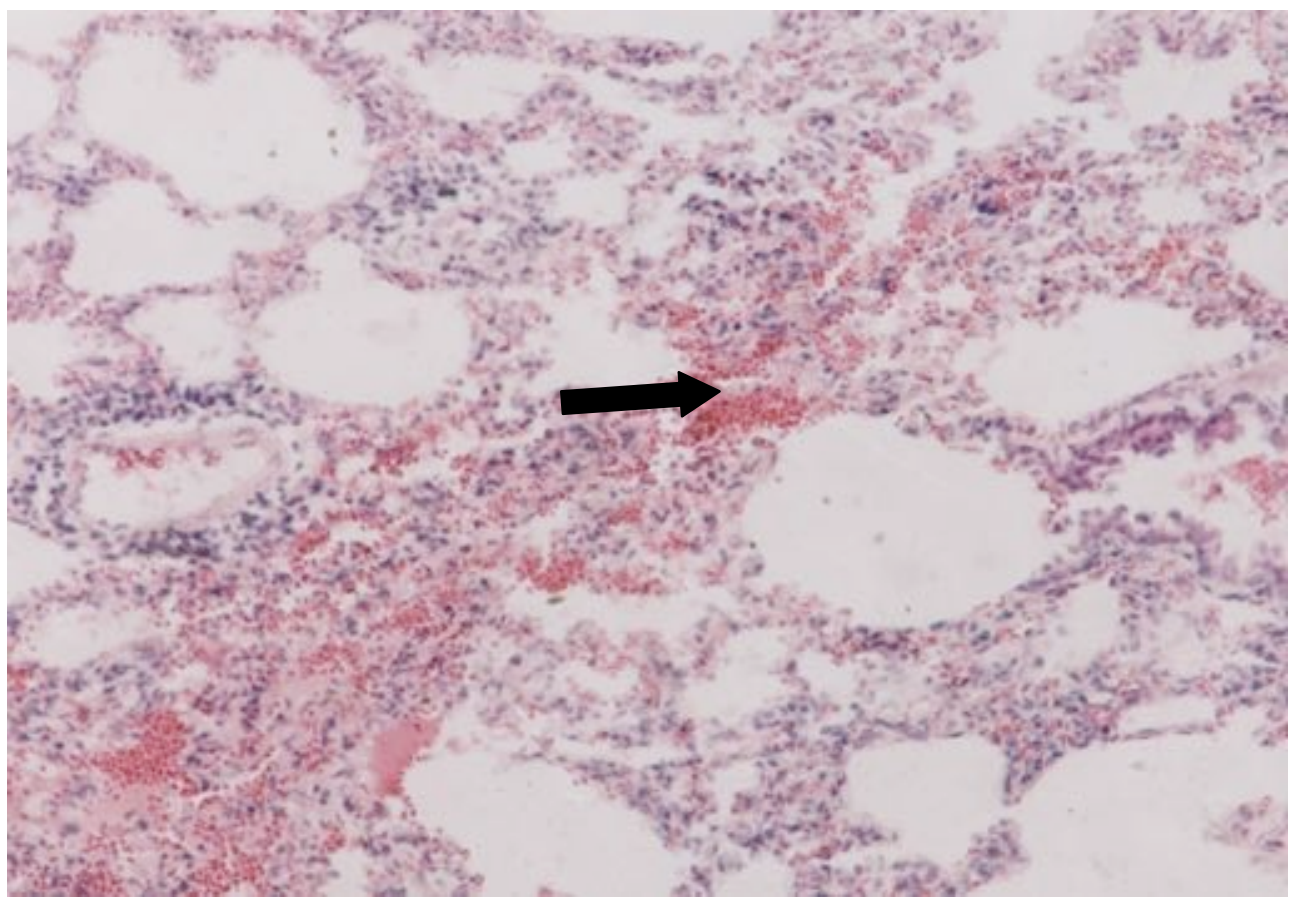

Figure (6): Photomicrograph of rat lung of sildenafil acute toxicity group showing massive interstitial haemorrhage (arrow), cellular infiltration and thickened alveolar septa (Hx.\&E X200). 


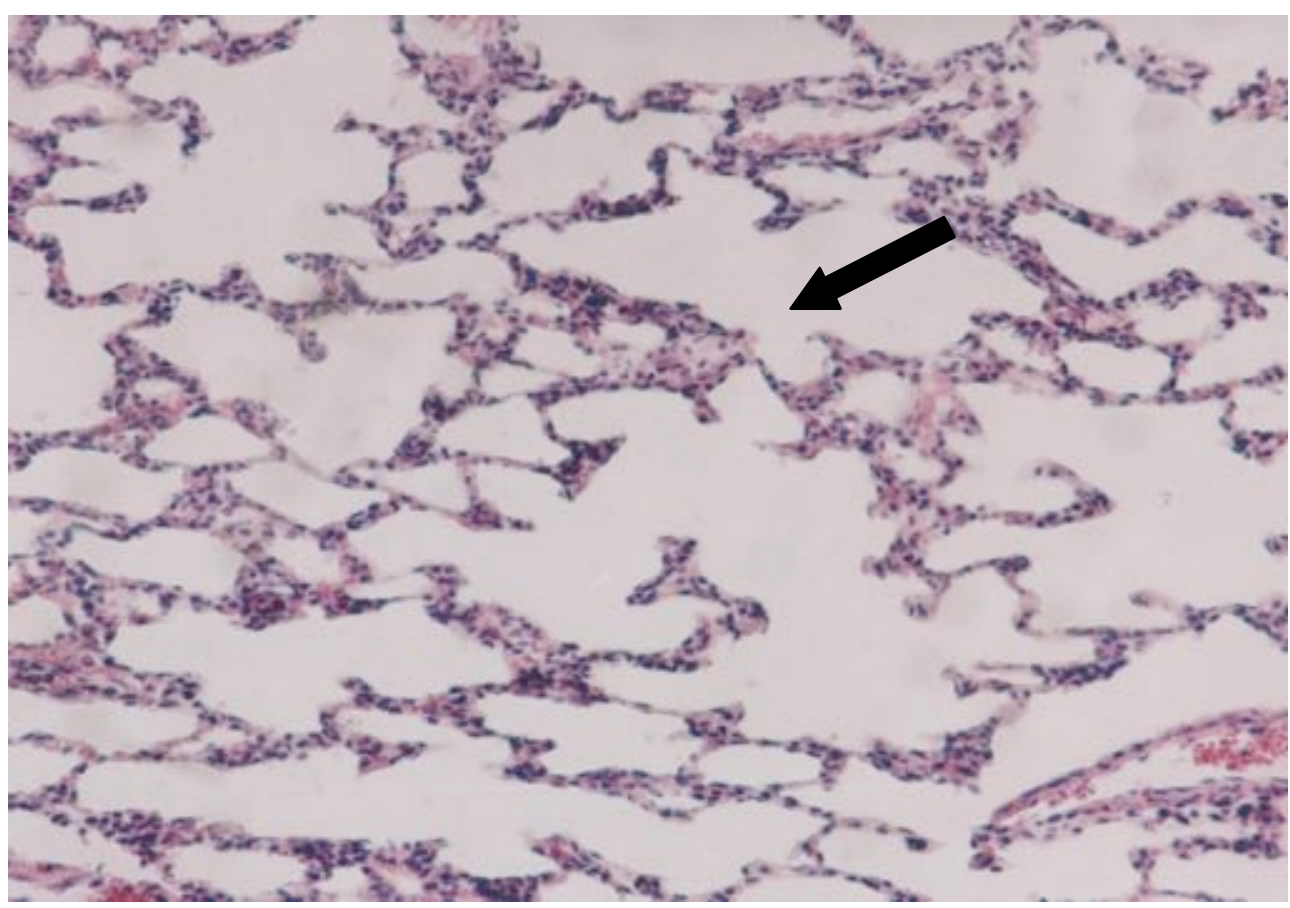

Figure (7): Another photomicrograph of rat lung of sildenafil acute toxicity group showing moderately thickened septa and mild cellular infiltration (arrow) (Hx. \& E X200).

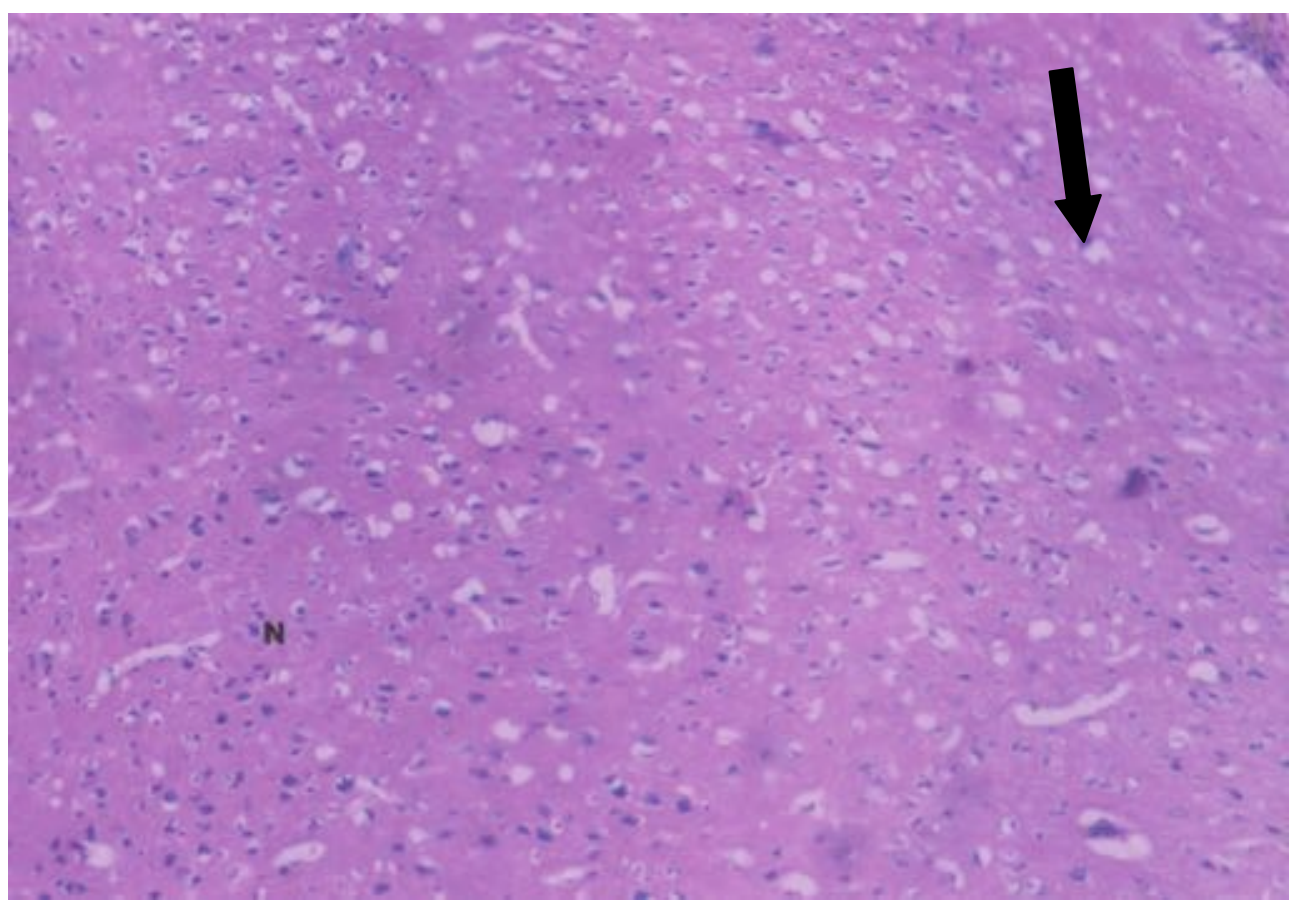

Figure (8): Photomicrograph of rat brain given acute toxic dose of sildenafil showing mild shrinkage of the neurons surrounded by vacuoles (arrow) and normal areas (N) (Hx. \&E X100). 


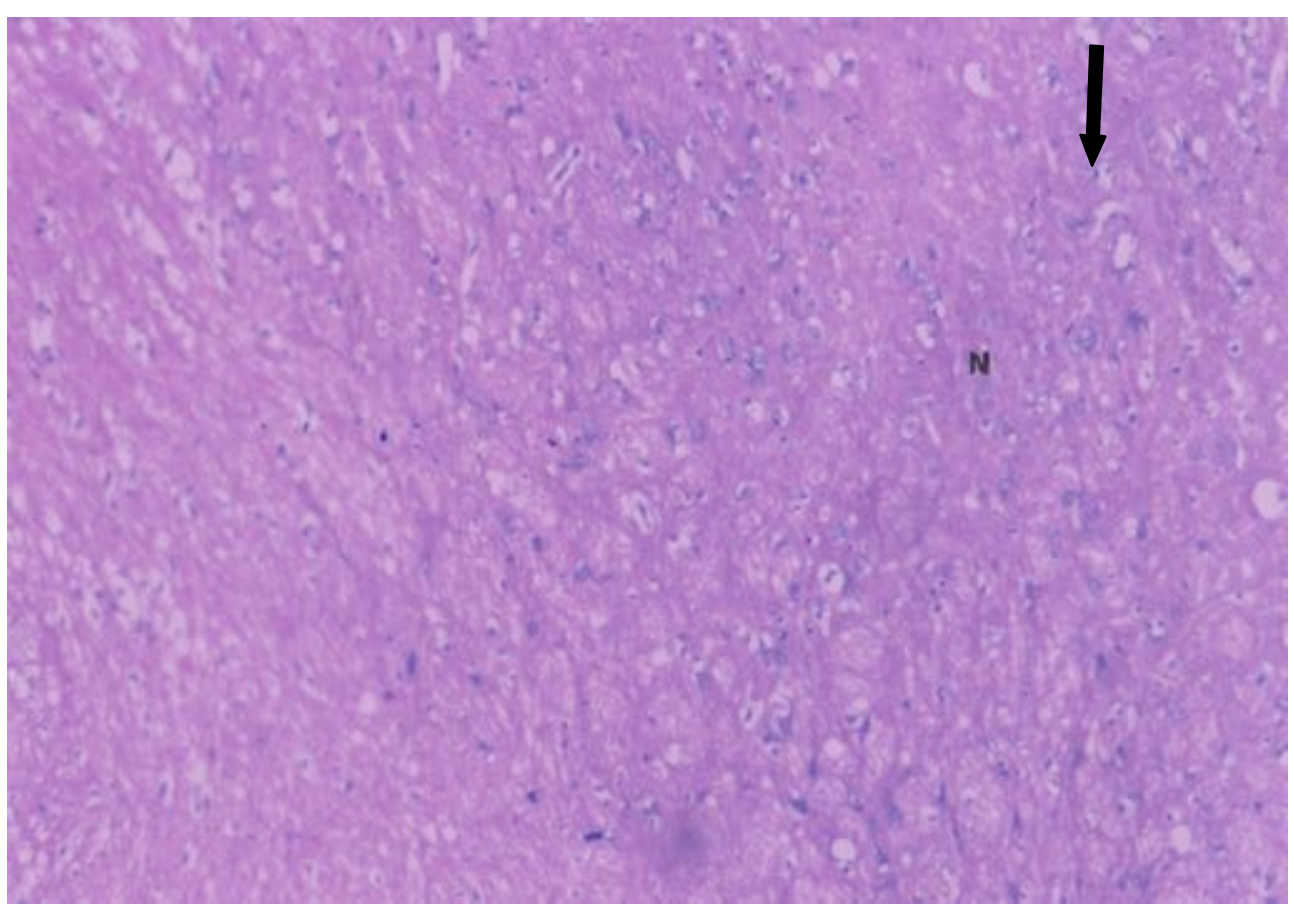

Figure (9): Another photomicrograph of the rat brain of the previous group showing marked shrinkage of the neurons; N (arrows) (Hx \& E X100).

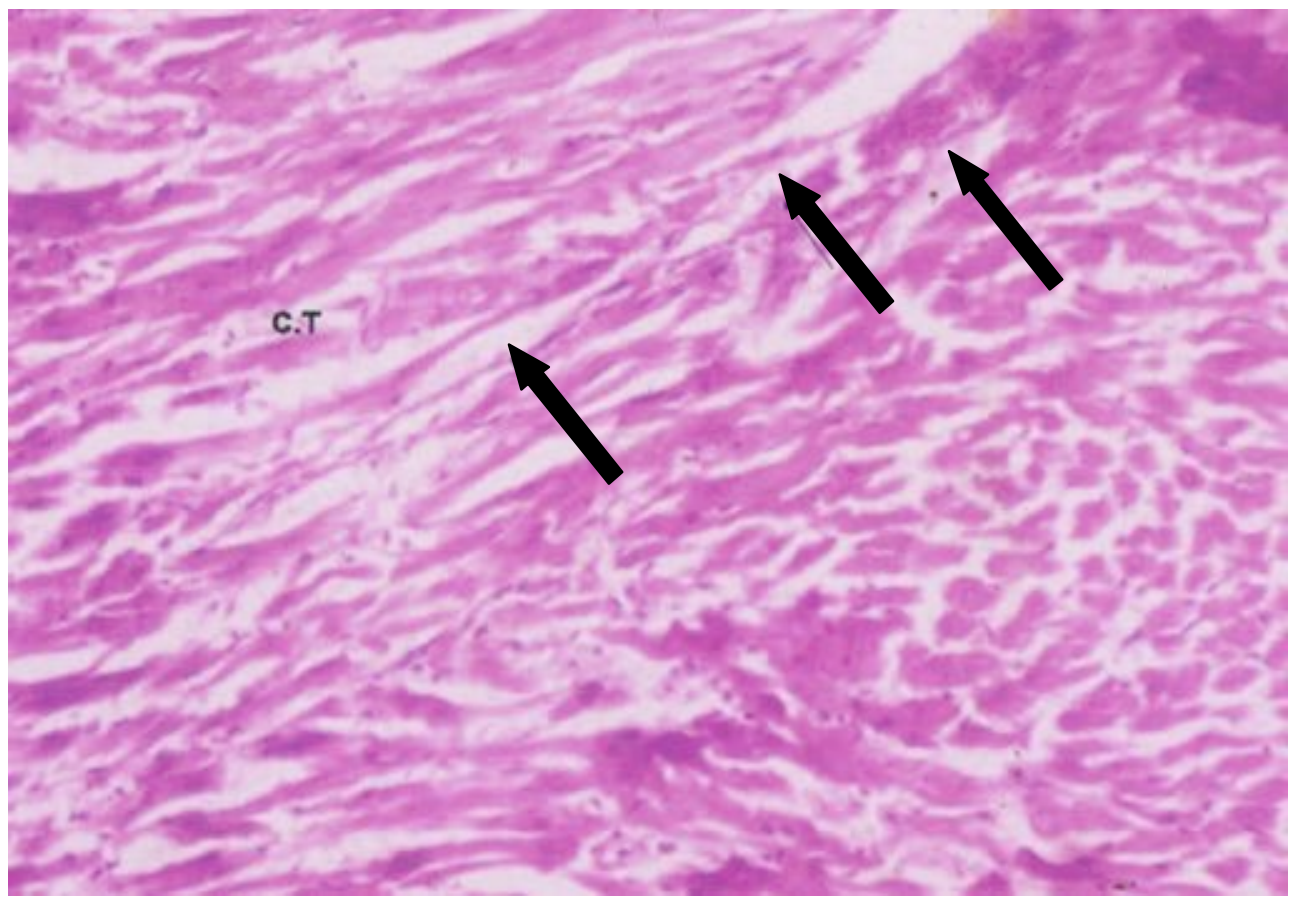

Figure (10): Photomicrograph of rat heart of short term sildenafil intoxicated group showing congestion in between the cardiac muscle fibres (arrow) and shrinkage of the cardiac muscle fibres with some connective tissues in between (CT) (Hx. \& E X100). 


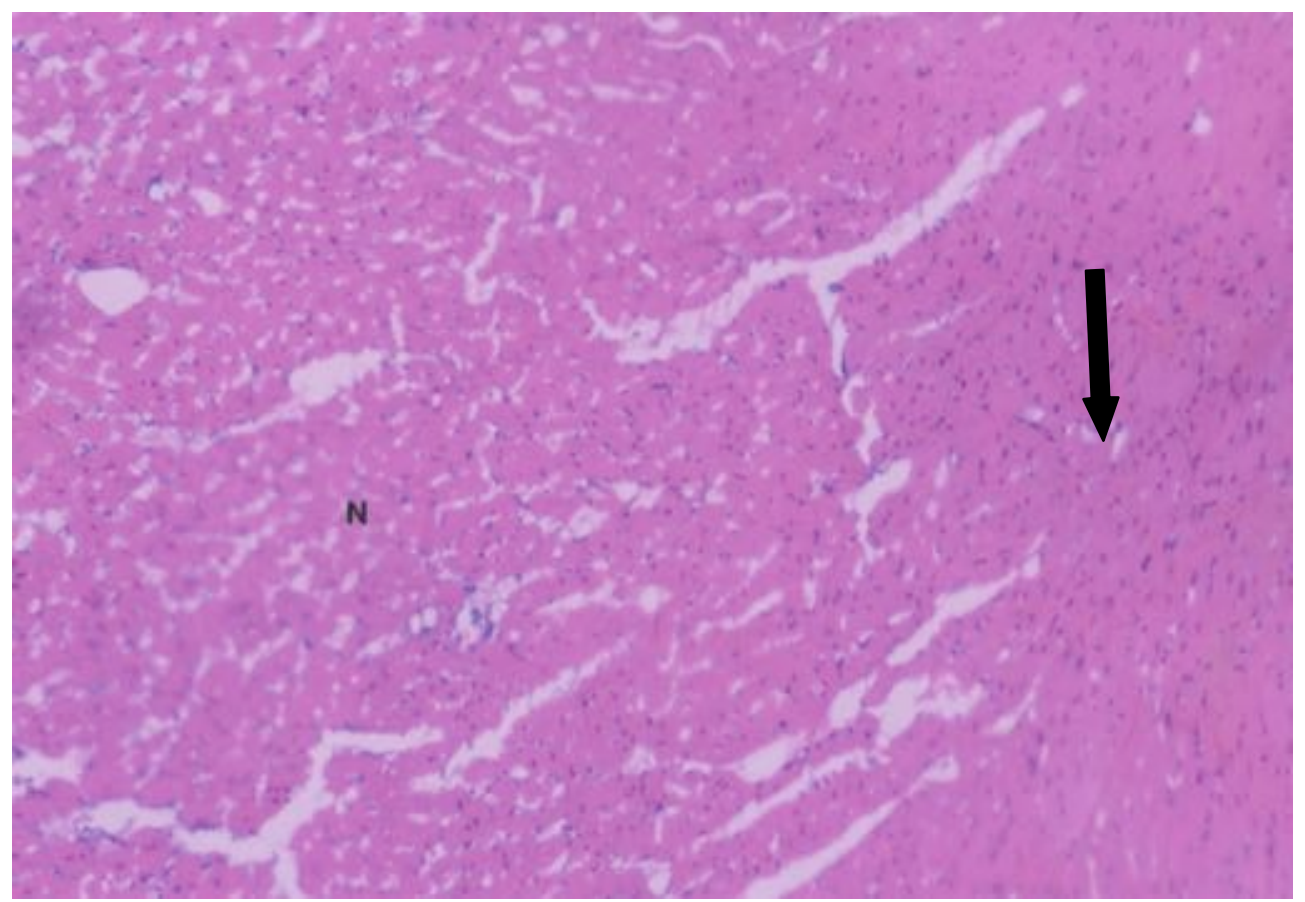

Figure (11): Another photomicrograph of rat heart of the previously mentioned group showing cloudy swelling of the cardiac muscle fibres (arrow). Few muscle fibres are nearly within normal appearance (N) (Hx. \&E X100).

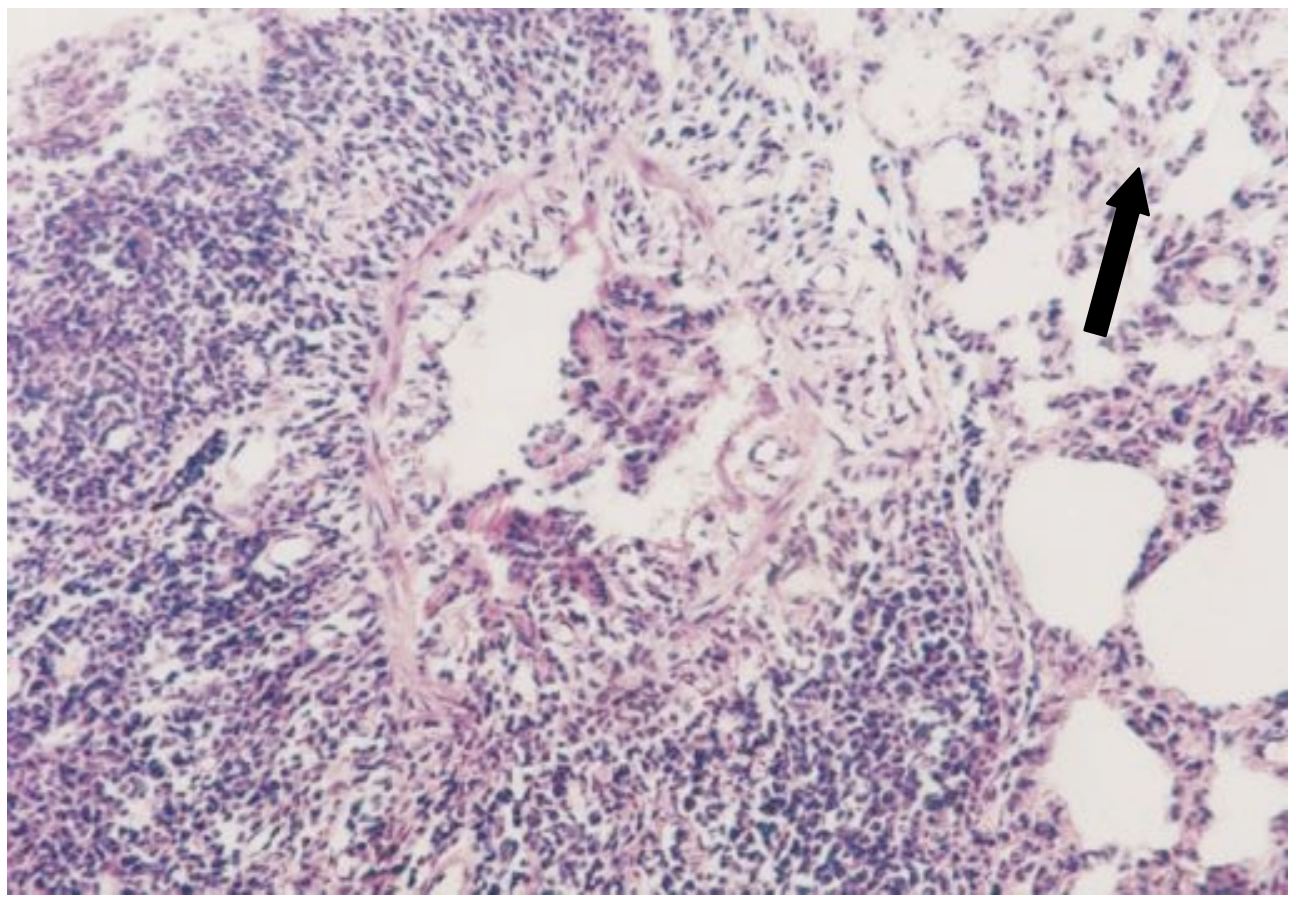

Figure (12): Photomicrograph of rat lung of short term sildenafil intoxicated group showing peri bronchiolar cellular infiltration. Many alveoli appear collapsed with thickened inter alveolar septa. (Hx.\&E X200). 


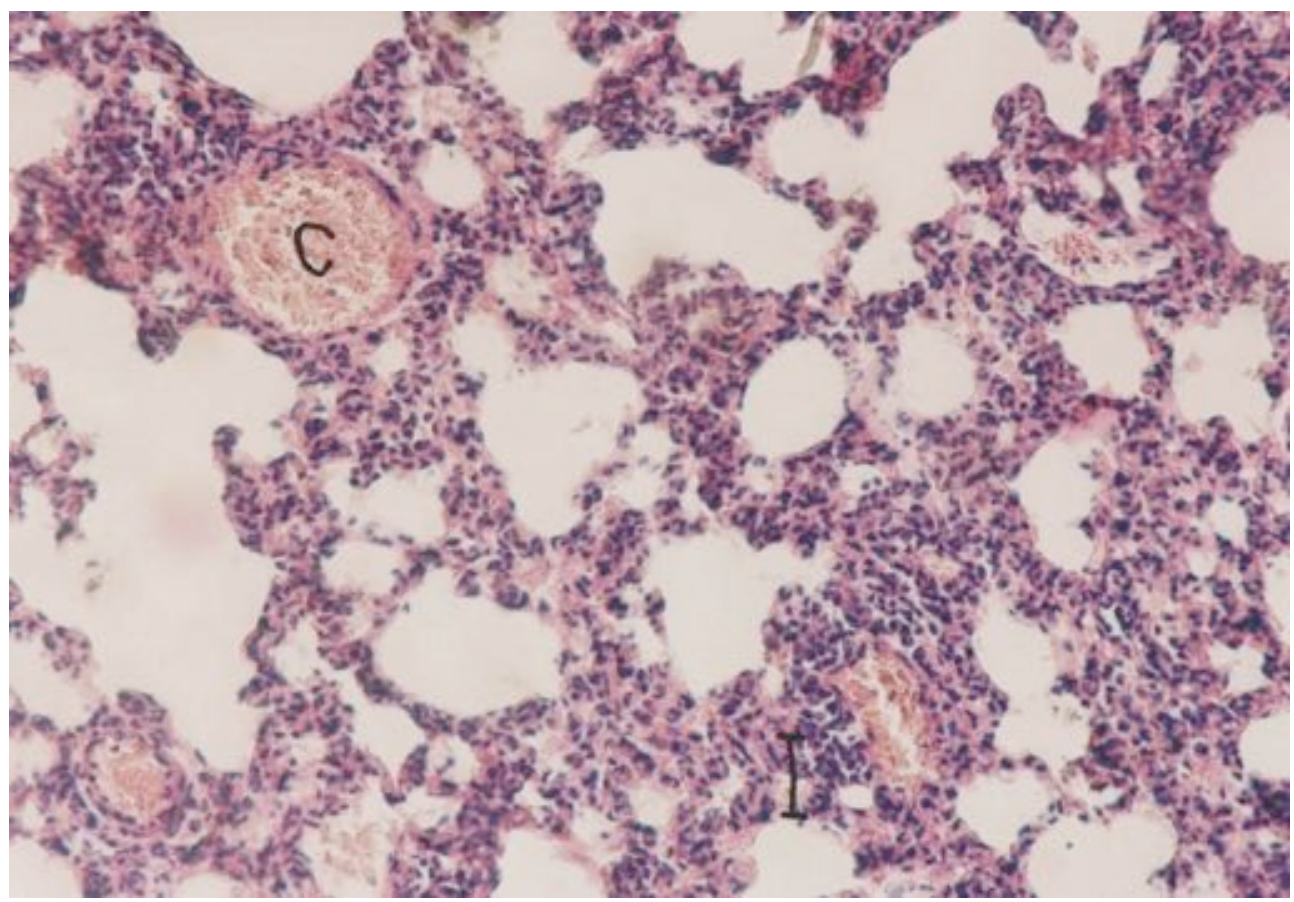

Figure (13): Another photomicrograph of rat lung of the same group showing marked congestion of most of the blood vessels (C) and perivascular cellular infiltration (I) together with collapsed alveoli and thickened septa (Hx. \& E X200).

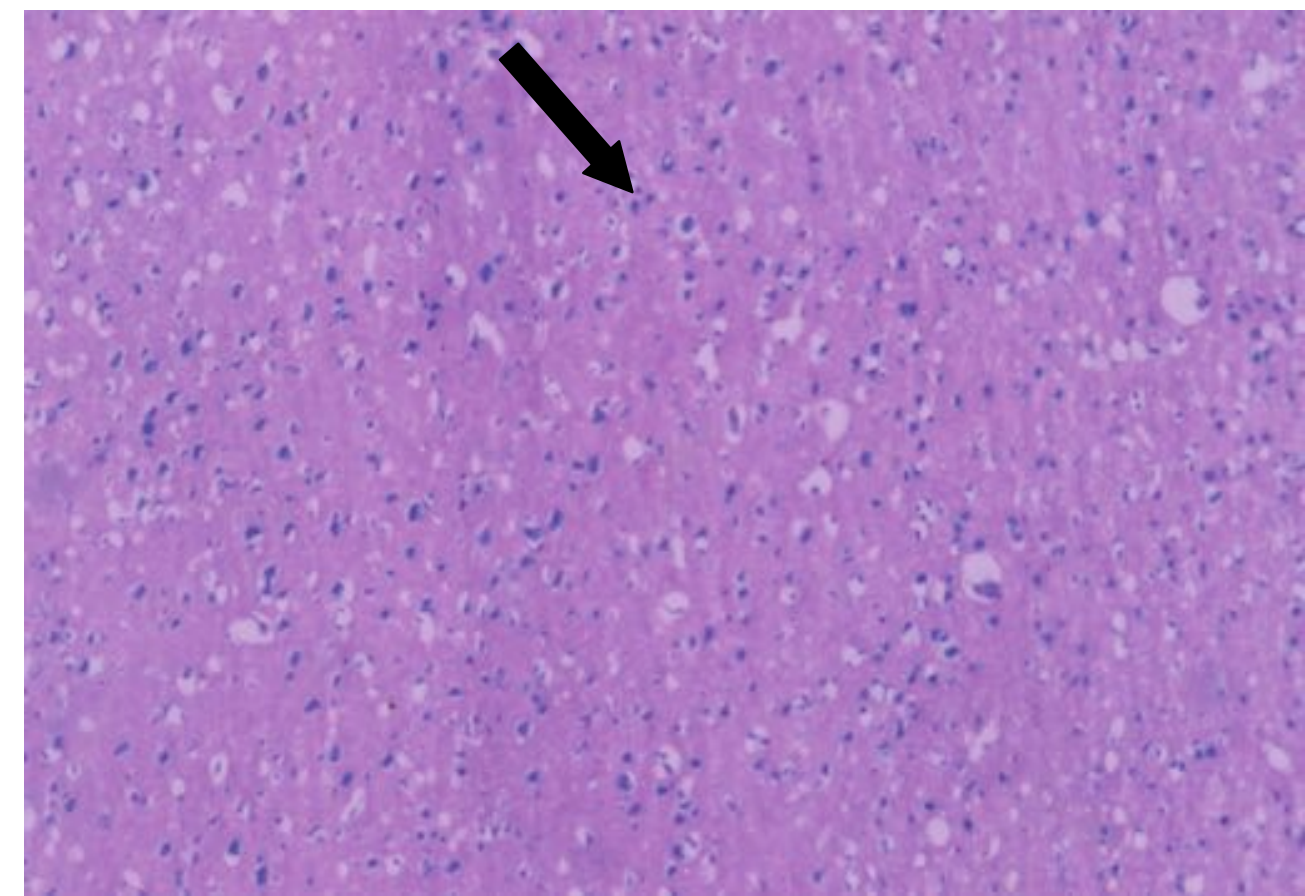

Figure (14): Photomicrograph of rat brain of the short term sildenafil group showing shrinkage of most of the neurons surrounded by vacuoles and inflammatory cells (arrow). 


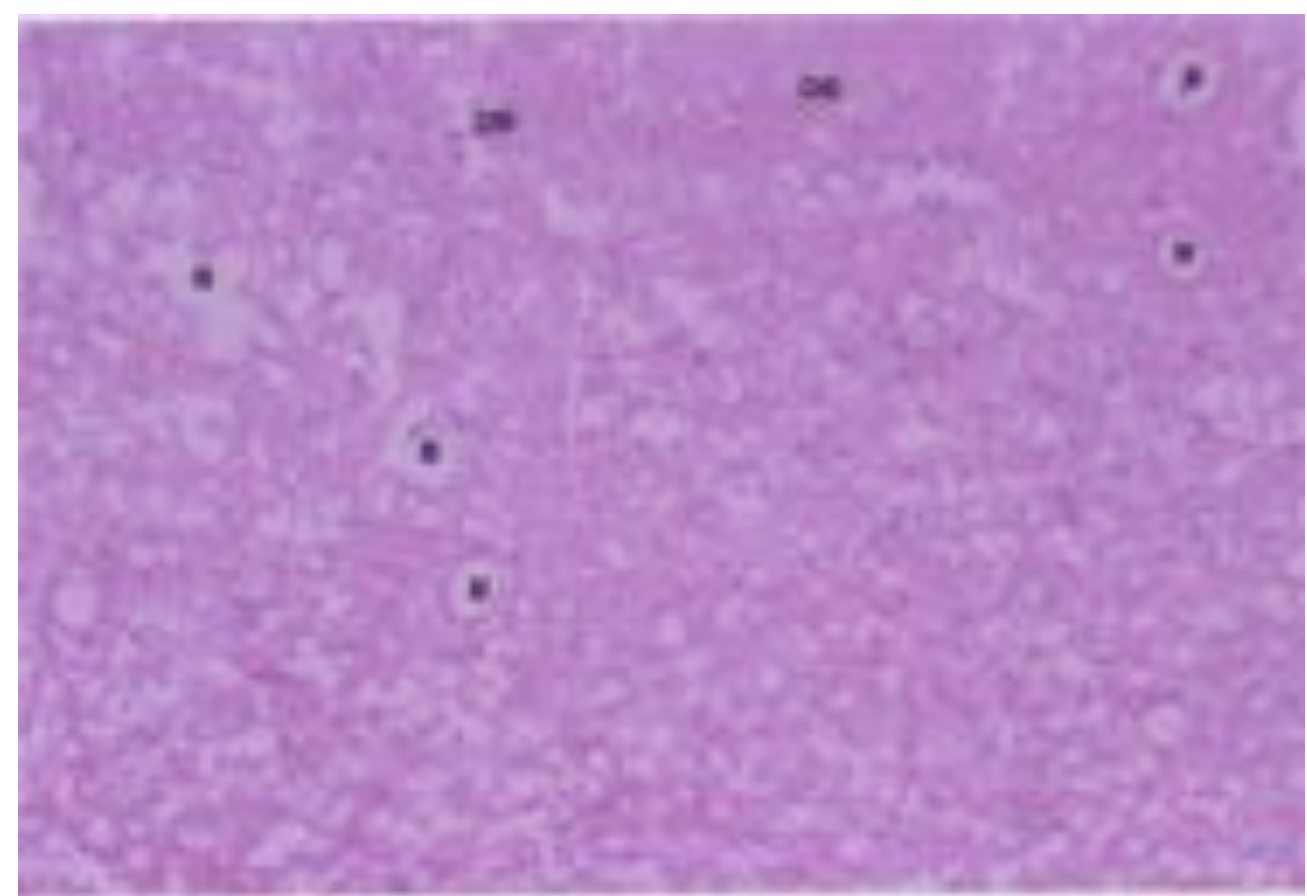

Figure (15): Another photomicrograph of rat brain of the previous group showing shrinkage of the neurons surrounded by vacuoles together with widened blood vessels (B) and slight areas of degeneration(DE) (Hx. \& $E$ X100).

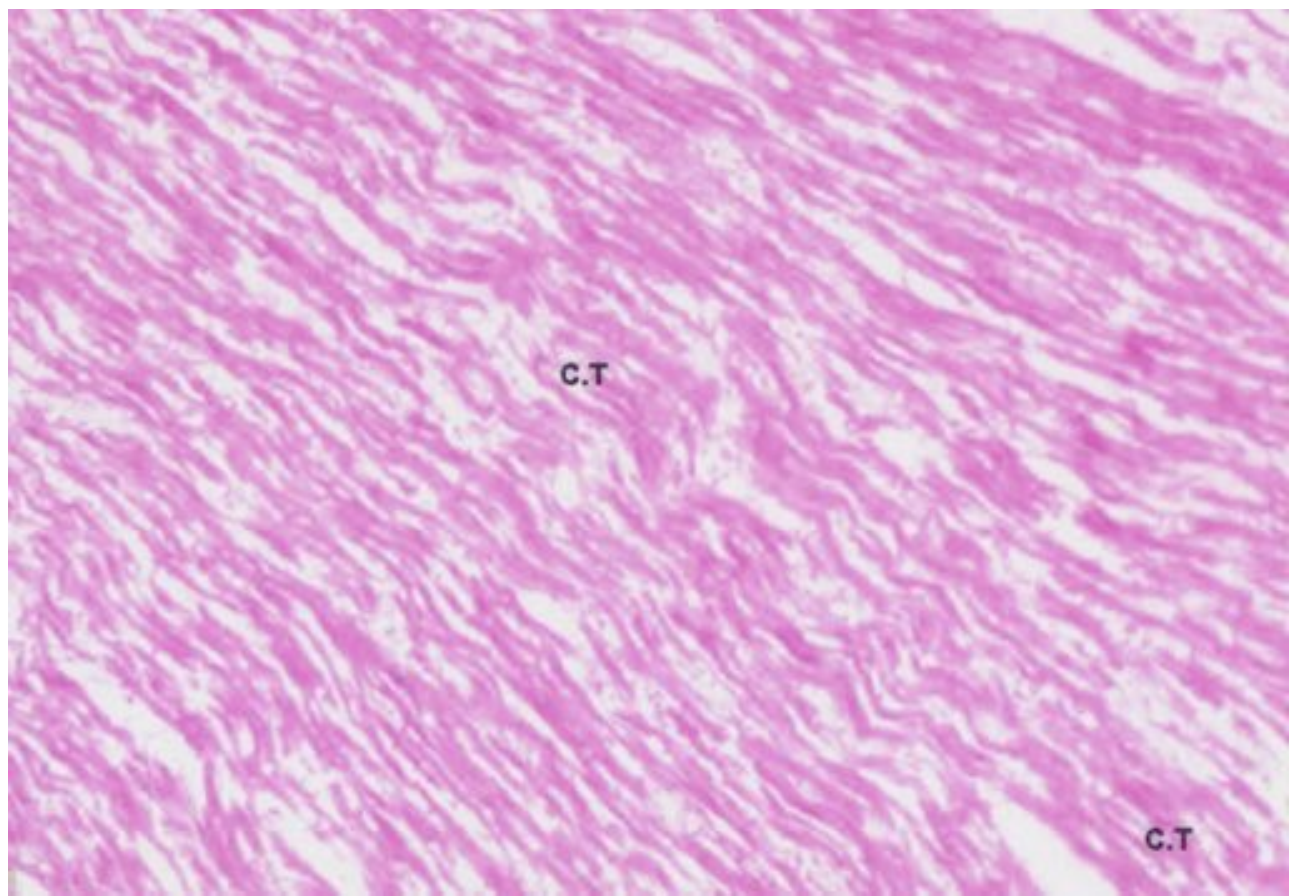

Figure (16): Photomicrograph of rat heart chronically intoxicated with sildenafil showing extensive shrinkage of cardiac muscle fibres and large amount of connective tissues in between (CT) (Hx. \& E X100). 


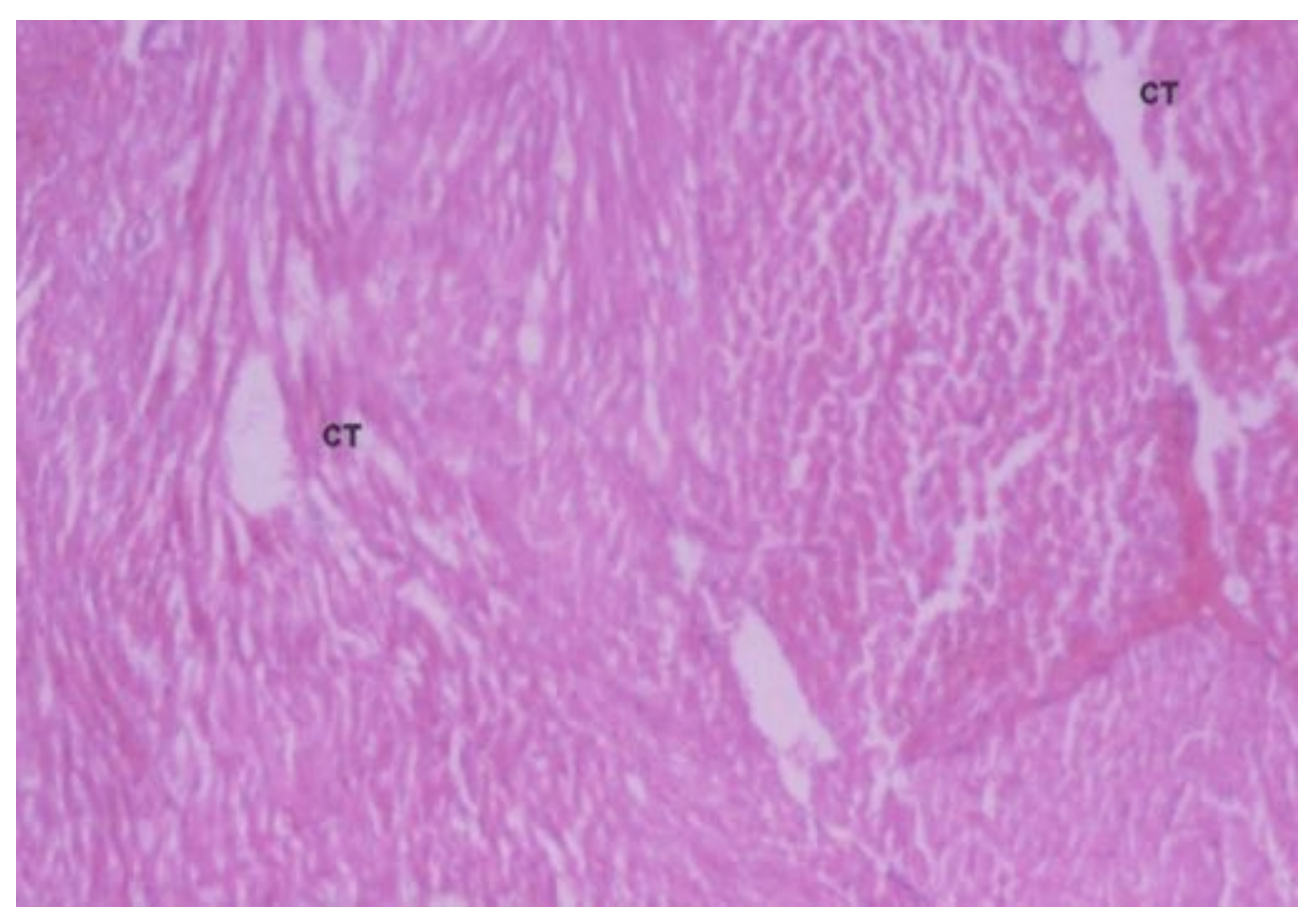

Figure (17): Another photomicrograph of rat heart of chronic intoxicated sildenafil group showing marked and extensive degeneration of cardiac muscle fibres and increased connective tissues in between (CT) (Hx. \& $\mathbf{E}$ X100).

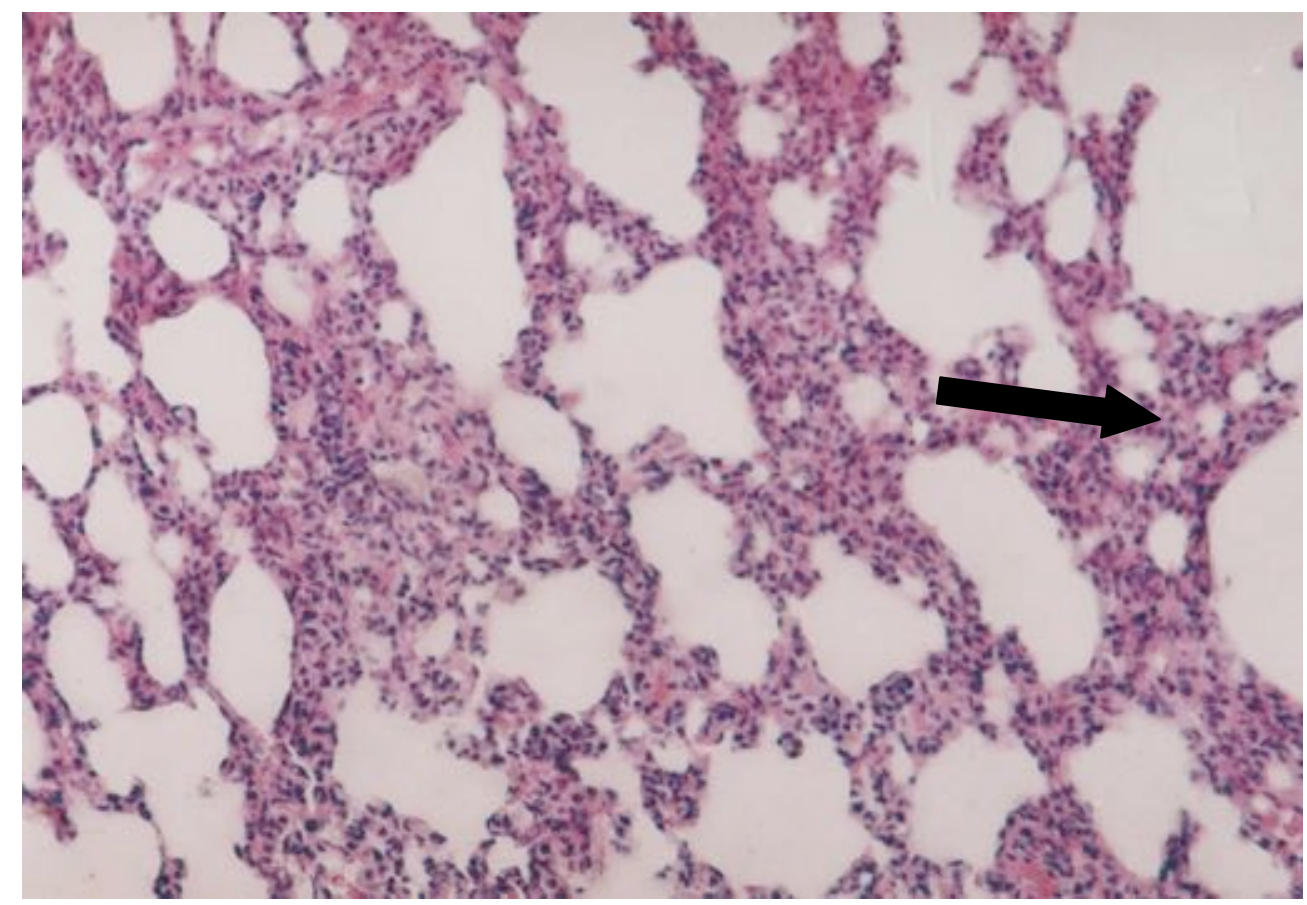

Figure (18): Photomicrograph of rat lung of chronic sildenafil toxicity group showing collapse of all the alveoli with marked thickening of the inter alveolar septa (Hx.\&E X200). 


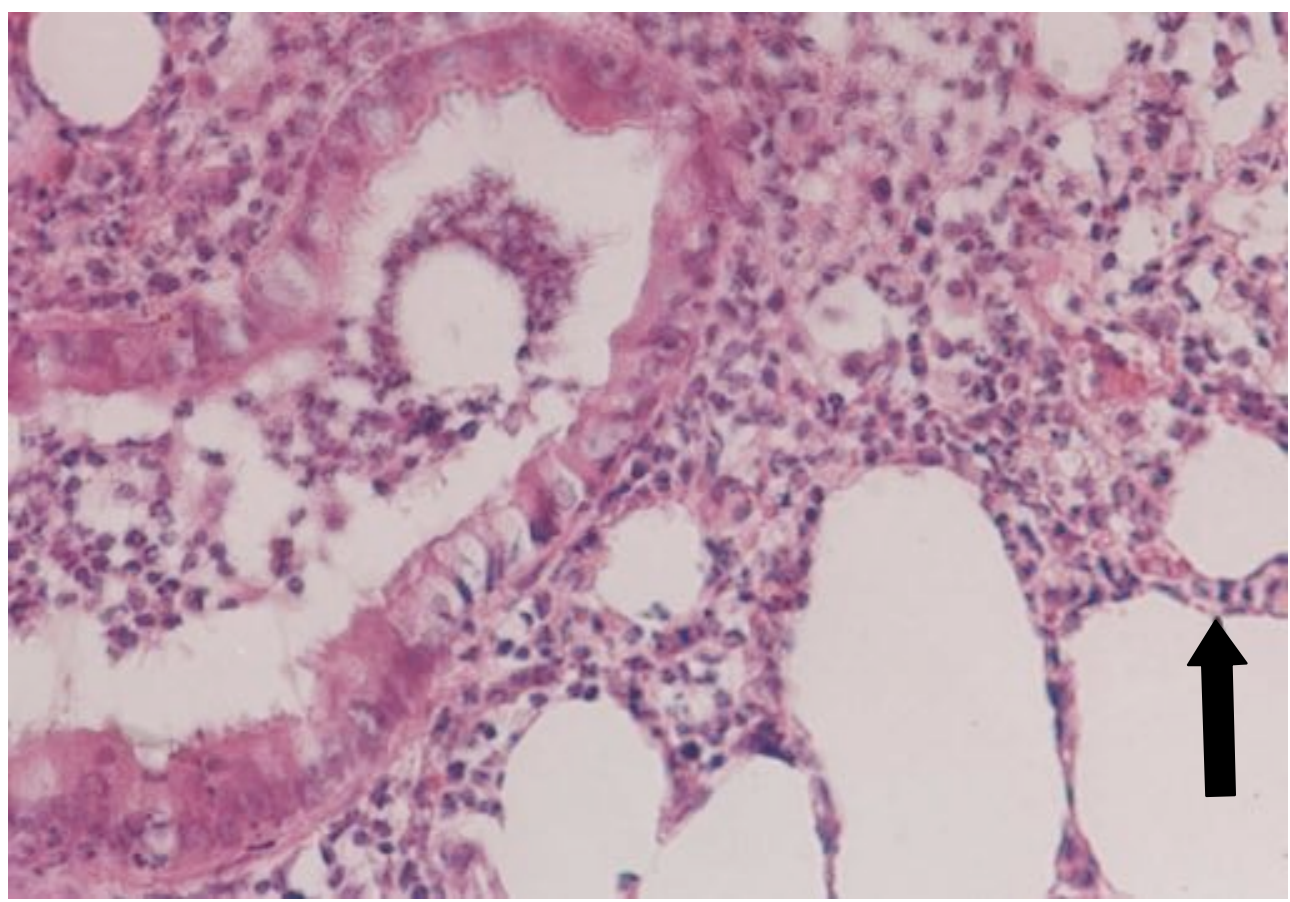

Figure (19): Another photomicrograph of rat lung of chronic sildenafil toxic group showing collapse of the alveoli with thickened inter alveolar septa (arrow). Notice marked cellular infiltration. A collapse of bronchi with cellular debris in its lumen (Hx.\&E X200).

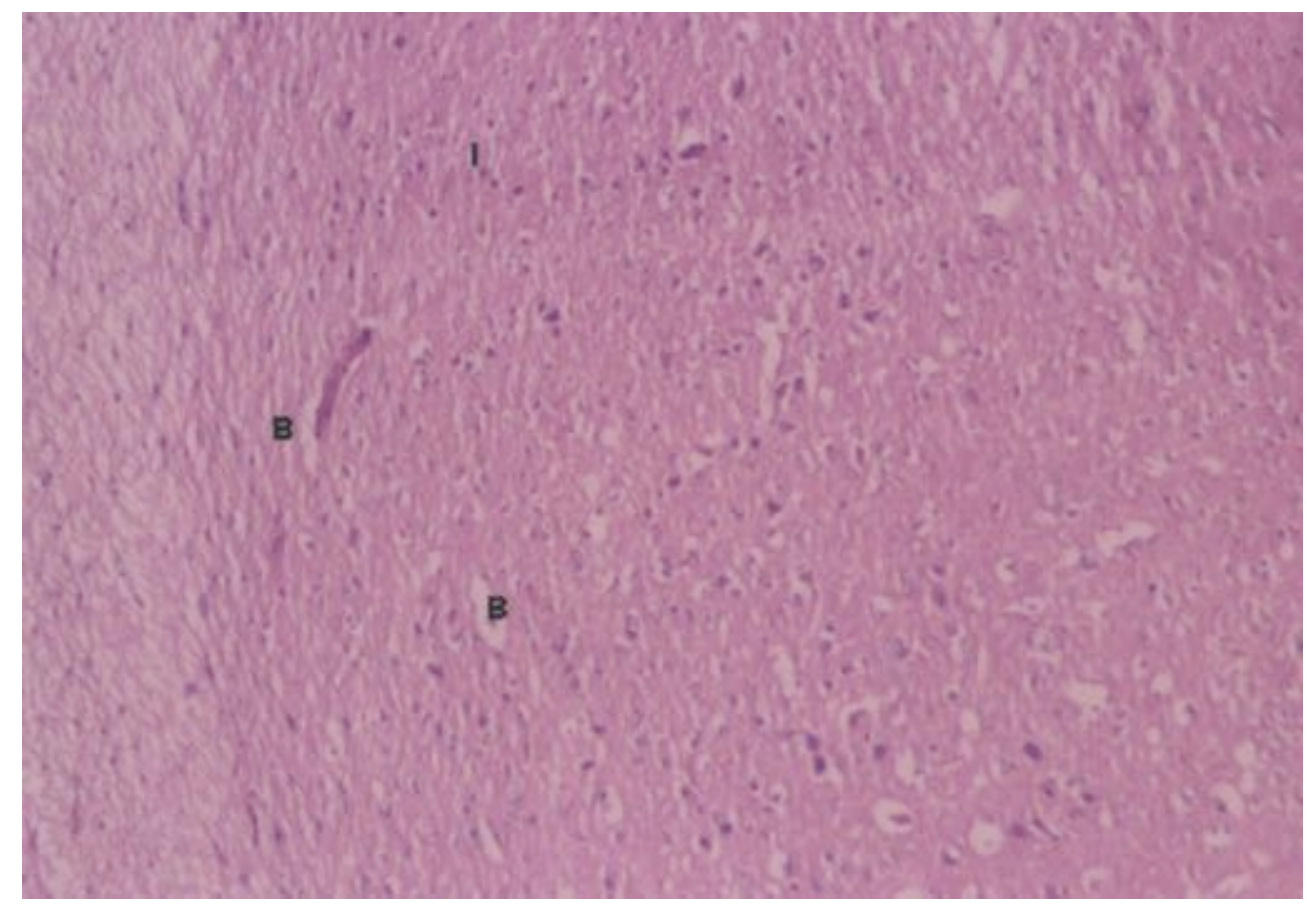

Figure (20): Photomicrograph of rat brain of chronic sildenafil toxicity group showing shrinkage of neurons and widened blood vessels (B) and chronic cell infiltration (Hx.\&E X100). 


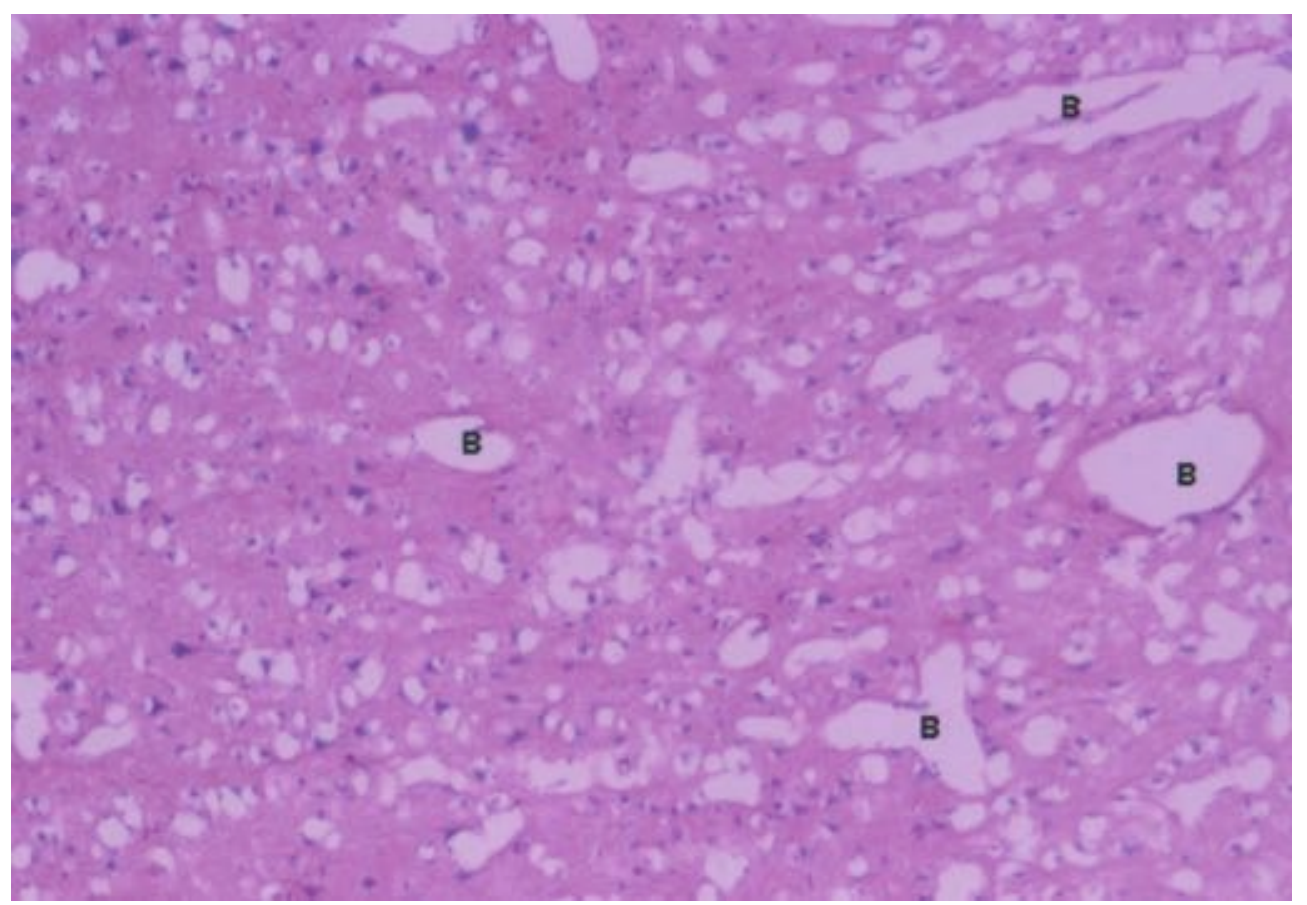

Figure (21): Photomicrograph of rat brain of the previous group showing marked degeneration of neurons with widened blood vessels (B) (Hx.\&E X100).

\section{Discussion}

\section{I-Acute toxicity study}

The results of the present study revealed evident cardiopulmonary and cerebral toxicities with acute toxic dose of sildenafil. Regarding the ECG changes, sinus tachycardia along with short QRS complex and depressed ST-segment were detected in experimental animals.. On recording blood pressure changes, all rats manifested with severe hypotension evidenced by a significant decrease in systolic and diastolic blood pressure in comparison with the control group. These findings agree with Jackson et al., (1999) who found that sildenafil induced marked decrease in systolic and diastolic blood pressure. Moreover, the authors reported that single oral dose ranging from 100 to 200 $\mathrm{mg}$ produced significant changes in the heart rate. Regarding QRS, Chiang et al., (2002) postulated that sildenafil adminstration in higher doses possesses direct cardiac electrophysiological toxic effects that change the cardiac repolarization. The depressed ST segment that has been recorded in the acutely intoxicated rats was characteristic of myocardial ischemia due to sildenafil (Geelen et al., 2000).

Moreover, the resultant cardiac toxicity due to acute toxic dose of sildenafil manifested by the significant increase in the CPK, CPKMB, LDH and SGOT enzyme levels was also described after Kekilli et al., (2005). They attributed their findings to sildenafil induced cardiac damage which is severe enough to cause myocytes cell membrane to rupture, allowing cardiac enzymes; CPK, CPKMB and SGOT to diffuse into the extracellular space. Furthermore, the authors stated that the elevation of serum CPKMB is directly related to the extent of myocardial necrosis and its elevation more than $6 \%$ of the total CPK is an early indicator of cardiac toxic insult. In addition, Moss and Handerson (1996) stated that the myocardial toxicity is usually associated with elevation of total serum LDH levels. Moreover, Klabunde (2011) stated that CPKMB in cases of acute toxic myocardial damage takes 4-6 hours to increase above the upper reference limit. Peak levels occur at nearly 24 hours. Also LDH begin to rise 12-18 hours, peak levels occur 24-48 hours of the cardiac ischemic events.

Histopathological examination of the heart showed severe toxic myocarditis represented by cloudy swelling, congestion of the blood vessels. Regarding the histopathological finding of the lung tissues, severe collapse of the alveoli together with pulmonary oedema and haemorrhage were found. The same changes were described by Bonow et al., (2001) who reported that after 24 hours of myocardial ischemia induced by sildenafil, the myocardium showed cloudy swelling with round cell infiltration. The changes detected in the lung tissues is a direct complicate of acute myocardial ischemia (Schneider et al., 2009). Regarding the brain tissues, there was mild shrinkage of some neurons. The results go hand in hand with Schultheiss et al., (2001) who reported that sildenafil did not reveal severe effects on the brain in acute dose, while Arnavez et al., (2003) reported that sildenafil induced cerebral histopathological changes.

\section{Il-Short term toxicity}

After eight weeks of administration, sildenafil induced a significant increase in the heart rate, depressed ST segment and shortening of the QRS duration. It was noticed from the above mentioned results that repeated 
doses of sildenafil induced further changes in ECG and blood pressures and worsen the toxic myocardial damage. Also the cardiac enzyme; SGOT showed a significant increase when compared with either control or acute toxic dose group. Light microscopic examination of the heart showed increased congestion in between the cardiac muscle fibres and the appearance of connective tissues in between denoting thickening of the vascular wall. Also lung tissues showed marked congestion, collapsed alveoli and cellular infiltration. The same results were recorded by Moss and Handerson (1996). In addition, histopathological changes of the current study were also described by Awan et al.,(2000) who attributed these changes to sildenafil induced myocardial ischemia or sympathetic over activity with ischemia.

Wolfe et al., (1998), reported that sildenafil may induce severe pericarditis and myocarditis and it seems to be closely related to inhibition of PDE2 that is located in the vascular smooth muscle in the heart. Phillips et al., (2000) suggested that pulmonary changes were due to the cardiovascular toxicity associated with sildenafil use.

Histopathological findings of the brain of this group were in the form of marked shrinkage of the neurons and cellular infiltration. Milman and Arnold (2002) described the same change in the rat brain after sildenafil administration for 8 weeks and reported that an increased duration of sildenafil use produced an increase in the incidence and severity of cerebral toxicity.

\section{III-Chronic toxicity study group}

The animals of this group showed further aggravation of the cardiopulmonary and cerebral toxicity of sildenafil which was evident on comparing chronic sildenafil toxicity group with short term groups. It was noticed by significant change in the ECG abnormalities in the heart rate, reduction of both systolic and diastolic blood pressure. The significant increase of the cardiac enzymes ;CPK,CPKMB and SGOT when compared with control or short term groups denoting that sildenafil administration for longer duration aggravated the myocardial toxicity. The same results were obtained by Shakir et al., (2003) found that the toxic effects of sildenafil were dose and time dependent.

In the current study the histopathological changes of the heart and lung were more severe than those noticed with either the acute or short term study groups as the heart tissues showed marked cloudy swelling, shrinkage and increased amount of connective tissues in between the cardiac muscles and the vessels. The pulmonary histopathological changes were also aggravated with collapse of nearly almost all the alveoli, collapsed bronchioles, thickened inter alveolar septa and marked chronic cellular infiltration. These pulmonary histopathological changes were also detected by Schneider (2009), who stated that the heart and the lung make up in a separable anatomic and functional unit. The changes of one can affect the other.
In contrast, Anderson and Stief (2000) and Tran and Howes (2003) reported that the toxic effect of sildenafil on the myocardium is not so severe and should be further investigated.

Regarding the histopathological changes of the brain, they were also intimated with repeated doses of sildenafil, in the form of marked shrinkage and degeneration of the neurones and widening of small cerebral blood vessels. These results go hand in hand with those of Schultheiss et al., (2001) who stated that sildenafil administration resulted in a higher incidence of CNS effects that necessitates further studies. On the other hand, Zhang et al., (2002) reported that sildenafil administration evokes neurogenesis and even reduces the neurological deficits after stroke.

The cardio toxic effects of sildenafil could be explained by inhibition of cyclic guanosine monophosphate which is a specific phosphodiesterase enzyme (PDE2). This results in arteriovenous dilatation, with marked decrease in blood pressure and reflex tachycardia (Goldstien et al., 1998). Furthermore, inhibition of PDE2 by sildenafil increases the cGMP which is the second messenger for nitric oxide that is involved in blood pressure regulation (through its effect on the basal vascular smooth muscle tone) (Wallis et al .,1999). Nitric oxide is as an important product of reactive oxygen species, which is responsible for biological toxicity (Touyz and Briones, 2011). Another mechanism of sildenafil induced cardiotoxicity was suggested by Kekilli et al.,(2005) who reported that redistribution of arterial blood may lead to inadequate coronary perfusion with subsequent myocardial toxicity due to hypoxia .However, Mukherjee et al., (2012) postulated that sildenafil causes increase in the sympathetic nerve activity that is not baro reflex mediated, suggesting that this drug is able to elicit an autonomic imbalance of central origin that implicates for cardiovascular events associated with its use.

The mechanism by which sildenafil caused changes in the lung tissues can be explained after Schneider et al., (2009) who stated that the toxic effect of sildenafil on CVS leads to hypotension and myocardial infarction. Both induce pulmonary hypoxemia with resultant pulmonary congestion and / or oedema. Also Herrman et al, (2000) stated that the hemodynamic effects of sildenafil especially hypotension leads to pulmonary hypoxia with resultant pulmonary complications.

As regards the effects of sildenafil on the brain, Milman and Arnold (2002) reported that sildenafil can cross the blood brain barrier and exerts many biochemical and physiological hazards. Nevertheless, Arnavez et al., (2003) found that sildenafil inhibited the PDE5 in the brain with accumulatin of cGMP which changes the cerebral blood flow. The authors concluded that daily administration of sildenafil in its highest dose caused central nervous system toxic effects in the form of shrinkage of the neurons up to degeneration. Finally, 
Zusman et al., (1999) and Lorberboym et al., (2010) reported that hypotension after sildenafil use causes diminished cerebral perfusion with subsequent cerebral congestion.

\section{Conclusion}

According to the previously mentioned findings it was concluded that sildenafil acute over dose induces both biochemical and histopathological cardiopulmonary toxicities. It also induced histopathological changes in the lung and brain. These toxic effects become severe and progressive with sildenafil administration for longer duration as shown in short term and chronic toxicity study. So such toxicities are time dependent.

\section{Recommendations}

It can be recommended that sildenafil should be used only by medical prescription and not to be used as an over the counter drug. Periodic and regular ECG and blood pressure monitoring for sildenafil users should be carried on regularly for early detection of any hazards of the drug. Further investigations based on the safety use of this drug in humans are advised to be done.

\section{Acknowledgment}

We express our sincere thanks to Dr: Mona Ahmed, assistant professor in physiology department, Faculty of Medicine, Ain Shams University for her assistance in the practical part of the study.

\section{References}

Abbott D, Comby P, Charuel C.et al., (2004): Preclinical safety profile of sildenafil. International Journal of Impotence Research. 16:498-504.

Anderson KF and Stief C (2000): Penile erection and cardiac risk: pathophysiological and pharmacological mechanisms. Am J Cardiol. 36:23F-26F.

Arnavez R, Aurich A, Weissenborn K et al., (2003): Effect of Sildenafil on cerebral blood flow velocity. A Pilot Study. Psychiatry Res.122 (3): 207-209.

Awan GM, Caldcran E, Dawood G and Alpert MA (2000): Acute symptomatic atrial fibrillation after sildenafil citrate therapy in patient with cardiomyopathy. Am J Med Sci. 320(1): 6971.

Bonow R, Libby P, Many P et al., (2001): Braunwald's Heart disease: A Text Book of Cardiovascular Diseases. $6^{\text {th }}$ ed. Philadelphia. WB Saunders Company. pp:1189-1232.

Callbreath DF (1992): Clinical enzymology II ; use of Lactic dehydrogenase LDH enzymes in diagnosis. Methods of analysis. In Clinical Chemistry (A Fundamental Text Book). $2^{\text {nd }}$ ed. Calbreath DF (edr).WB Saunders Company.pp:210-214.

Chiang C, Luk H, Wang Tand Ding P(2002) : Cardiovascular Research. Effects of sildenafil on cardiac repolarization. 55:290-299.

Cuschieri A and Backer PP (1977): Introduction to Research in Medical Science. Churchill Livingstone. Edinburgh. London. New York.pp:16.

Dewall RA, Vasko KA, Stanley EL and Kezdi $\mathrm{P}(1971)$ : Responses of ischemic Myocardium to Allopurinal. Am Heart J. 3: 362-370.

Dewhurst DG, Hughes IE, Williams AD (1996): An interactive computer program to replace in vivo experiments on rat blood pressure for teaching undergraduate students. ATLA 24:707-714.

Drury RA and Wallington EA (1980): Periodic acid Schiff reaction phosphotungestic acid. In Carlton's Histological Technique. $5^{\text {th }}$ ed. Oxford University Press. Oxford. New York. pp: 146-147.

Fagelman E, Fagelman A and Shasigh R (2001): Efficacy, safety and use of sildenafil in urologic practice. J Urol. 57(6): 1141-1144.

Geelen P, Benait D, Rail J et al., (2000): Sildenafil prolongs cardiac repolarization by blocking the rapid component of the delayed rectifier potassium current. Circulation. 102: 275-277.

Ghosh MN (1971): Fundamentals of Experimental pharmacology. Scientific Book Ageny. Calcuta. pp: 1, 14, 70, 75.

Goldstein J, Lue T F, Pamdo NH et al., (1998): Oral Sildenafil in Erectile Dysfunction. Sildenafil study group. N Engl J.Med. 338 (20): 13971404.

Han BH, Vellimana AK, Zhou ML et al., (2012): Phosphodiesterase 5 inhibition attenuates cerebral vasospasm and improves functional recovery after experimental subarachnoid hemorrhage. Neurosurgery. 70(1):178-187.

Herrman HC, Chang G and Mahoney PD (2000): Hemodynamic effects of sildenafil in men with coronary disease. N Engl J M. 342 (22): 1622-1626.

Jackson G, Benyamin N, Jackson N, and Allen MJ (1999): Effect of sildenafil on human hemodynamics. Am J Cardiol.83 (5): 13-20.

Kekilli M, Beyazit Y, Purnak T et al., (2005): Acute myocardial infarction after sildenafil citrate ingestion .The Annals of Pharmacotherapy. 39(7-8) 1362-1364.

Khera M and Goldstein I (2011): Erectile dysfunction. Phunikhom K Clin Evid. 29: 1803.

Klabunde R (2011): Cardiovascular Integration, Adaptation and Pathophysiology. In: Cardiovascular Physiology Concepts, $2^{\text {nd }}$ ed. Lippincott. Williams and Wilkins. pp: 11781203. 
Kloner RA (2000): Sex and the patient with CVS risk factors: focus on sildenafil. Am J Med. 109 (9A): 13-30.

Lorberboym M, Mena I, Wainstein J et al., (2010). The effect of sildenafil citrate (Viagra) on cerebral blood flow in patients with cerebrovascular risk factors. Acta Neurol Scan.121:370-376.

Madduri MR (2001): After two years did sildenafil live up to its expectations? Mo. Med. 98 (6): 243245.

Marmon MR and Kessler R (1999) : Sildenafil and ophthalmology. Survey Ophth. 44(2): 153162.

Milman AA and Arnold SB (2002): Neurological, psychological and aggressive disturbances with sildenafil. The Annals of Pharmacotherapy. 36(7-8): 1129-1134.

Moss DW and Handerson AR (1996): Clinical Enzymology, CPK, LDH. In: Text Book of Clinical Chemistry. $23^{\text {rd }}$ ed. WB Saunders Co. pp: 657-673.

Mukherjee KK, Singh SK, Khosla VK et al.,(2012): Safety and efficacy of sildenafil citrate in reversal of cerebral vasospasm: A feasibility study. Surg Neurol Int. 3:3.

Osterloch I and Riley A (2002): Clinical update on sildenafil citrate. Br J Clin Phrmacol.53(3): 219-223.

Phillips BG, Kato M, Pesefe CA et al., (2000):Sympathetic activation by Sildenafil. Circulation. 102: 3068-3073.

Polak K, Wimpissinger B and Berisha F (2003): Effect of sildenafil on retinal blood flow and flickerinduced retinal vasodilatation in healthy subjects. Invest Ophthalmol Vis Sci. 44(11): 4872-4876.

Reitman S and Frankul S (1957): A colorimetric method for the determination of serum glutamic oxalacetic and glutamic pyruvic transaminases. Am J Clin Pathol. 28(1) 56-63.

Schneider HG, Lam L, Lokuge A et al. (2009):B-type natriuretic peptide testing, clinical outcomes, and health services use in emergency department patients with dyspnea: a randomized trial. Ann Intern Med.150(6):365371.

Schultheiss D, Muller SV and Nager W (2001): Central effects of sildenafil on auditory selective attention and verbal recognition memory in humans. A study with event- related brain potentials. World J Urol. 19(1): 46-50.

Shakir SAW, Wilton LV, Boshier A et al., (2003): Cardiovascular events in sildenafil users results from the first phase of prescription event monitoring in England. BMJ. 322: 651652.

Touyz R and Briones A (2011): Reactive oxygen species and vascular biology: implications in human hypertension. Hypertension Research. 34: 5-14.

Tran D and Howes LG (2003): Cardiovascular safety of sildenafil. Drug Saf. 26:453-460.

Vardi Y, Klein L, Nassar S, et al., (2002): Effects of sildenafil citrate (viagra) on blood pressure in normotensive and hypertensive men. 59 (5) : 747-752.

Wallis RM, Corbin JD, Frances SH and Ellis P (1999): Tissues distribution of PDE families and and the effects of sildenafil on tissue cyclic nucleotides, platelet function, and the contractile responses of trabeculae carneae and aortic rings in vitro. The American Journal of Cardiology. 83(5): 3-12.

Wolfe SM, Sasich L and Barbehenn E (1998): Safety of sildenafil citrate. Lancet. 352(9137):1393.

Wolfson D, Lindberg E, Su L et al., (1991): Three rapid immunoassay for determination of creatine phosphokinase: An analytical clinical and interpretive evaluation. Am Heart J. 122(4):958-964.

Zhang R, Wang Y and Zhang L (2002): Sildenafil induces neurogenesis and promotes functional recovery after stroke in rats. Stroke. 33 (11). 2675-2680.

Zusman RM, Morales A and Glasser DB (1999): Overall cardiovascular profile of sildenafil citrate. Am J Cardiol. 83(5): 35-44.

\section{الملخص العزبي}

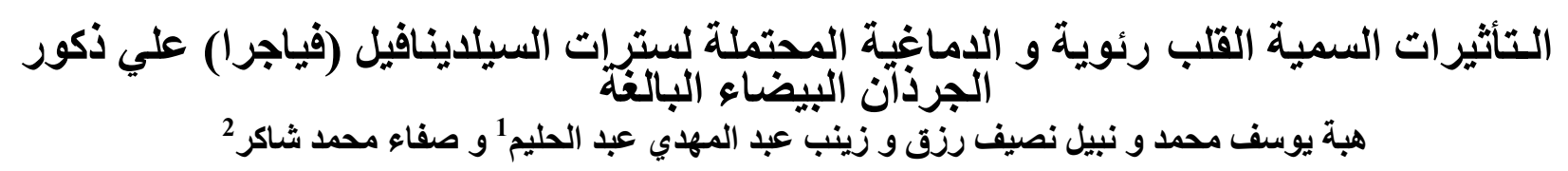

هنالك تساؤل عما إذا كانت سلامة عقار السيلدينافيل ترفي إلى مستوى التوقعات أم لا. ذكرث أت دعظد

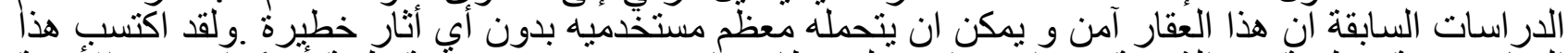

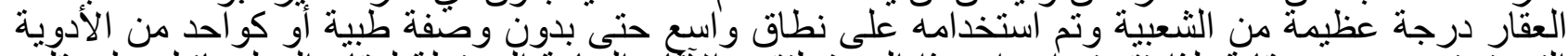

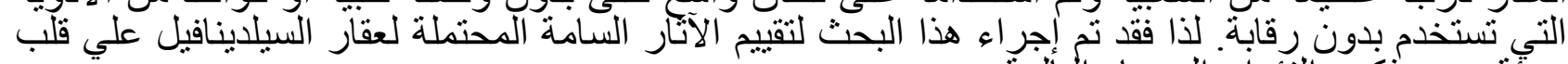

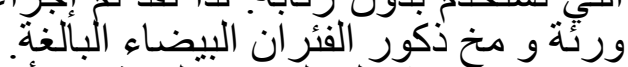

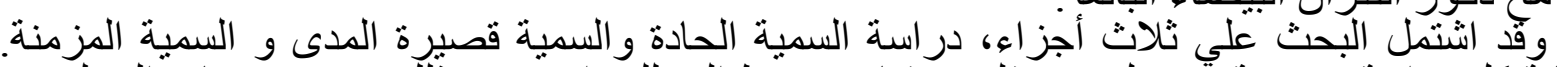

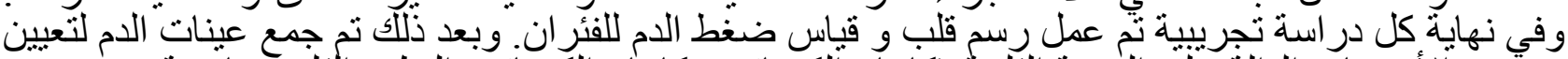

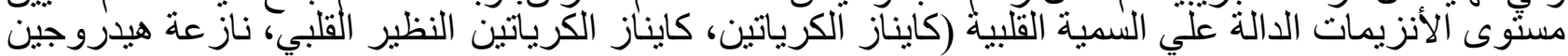




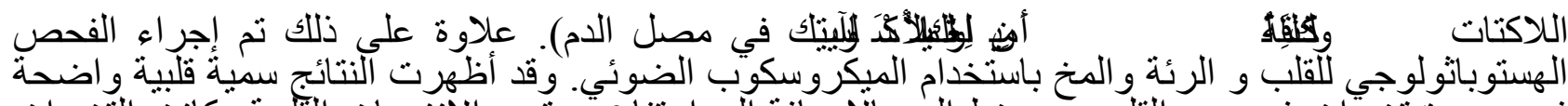

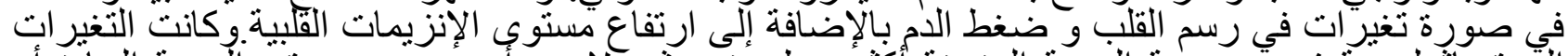

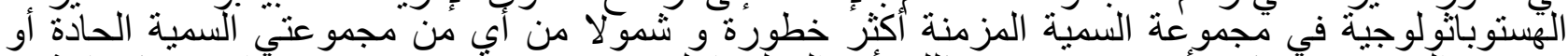

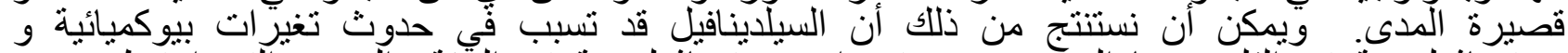

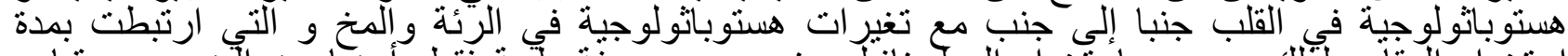

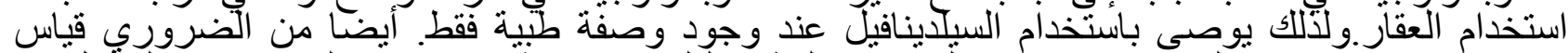

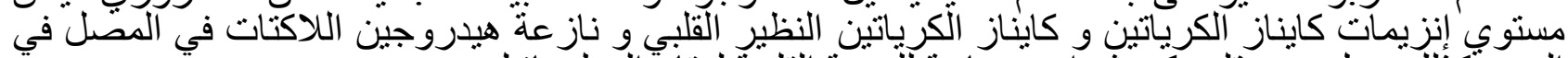

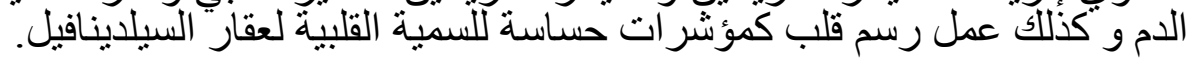

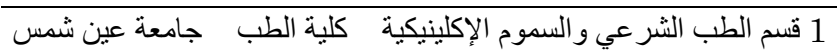

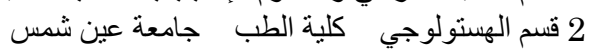

